\title{
Use of transethosomes for enhancing the transdermal delivery of olmesartan medoxomil: in vitro, ex vivo, and in vivo evaluation
}

This article was published in the following Dove Medical Press journal: International Journal of Nanomedicine

\author{
Rofida Albash ${ }^{1}$ \\ Aly A Abdelbary 2,3 \\ Hanan Refai' \\ Mohamed A El-Nabarawi ${ }^{2}$ \\ 'Department of Pharmaceutics, \\ College of Pharmaceutical \\ Sciences and Drug Manufacturing, \\ Misr University for Science and \\ Technology, Giza, Egypt; ${ }^{2}$ Department \\ of Pharmaceutics and Industrial \\ Pharmacy, Faculty of Pharmacy, Cairo \\ University, Cairo, Egypt; ${ }^{3}$ Department \\ of Pharmaceutics and Industrial \\ Pharmacy, Faculty of Pharmacy, \\ October 6 University, Giza, Egypt
}

Correspondence: Mohamed A

El-Nabarawi

Faculty of Pharmacy, Cairo University,

Kasr El-Ainy Street, Cairo I I562, Egypt

Tel +20 I0 01424439

Email mohamedmohy1965@gmail.com
Introduction and aim: Olmesartan medoxomil (OLM) is an antihypertensive drug with low oral bioavailability due to extensive first-pass metabolism. This study aimed to prepare transethosomes (TEs) for enhancing the transdermal delivery of OLM to avoid its oral problems. Methods: TE formulae were prepared utilizing $5^{1} \cdot 3^{1}$ full factorial design using various surfactants (SAAs) and different phospholipid-to-SAA ratios. The formulae were characterized regarding their entrapment efficiency percentage (EE\%), particle size (PS), polydispersity index (PDI), zeta potential (ZP), and the amount of drug released after 6 hours (Q6h). Design Expert ${ }^{\mathbb{R}}$ software was employed to select the optimum formula.

Results: The optimum formula (TE14) had an EE\% of $58.50 \% \pm 1.30 \%$, PS of $222.60 \pm 2.50$ $\mathrm{nm}$, PDI of $0.11 \pm 0.06$, ZP of $-20.80 \pm 0.30 \mathrm{mV}$, and Q6h of $67.40 \% \pm 0.20 \%$. In addition, TE14 was compared to transferosomes (TFs) in terms of elasticity and was found to show higher deformability index. Further, evaluation of ex vivo permeation using both rat and shed snake skin showed higher permeability of TE14 compared to TFs and OLM suspension. Confocal laser scanning microscopy confirmed the capability of the fluoro-labeled TE14 to penetrate deep within the skin, while the histopathological study confirmed its safety. TE14 successfully maintained normal blood pressure values of rats up to 24 hours. Moreover, TE14 showed superiority in dermatokinetic study when compared with drug suspension.

Conclusion: Taken together, the obtained results confirmed the potential of employing TEs as a successful carrier for the transdermal delivery of OLM.

Keywords: olmesartan medoxomil, transethosomes, factorial design, transdermal drug delivery, dermatokinetic study, confocal laser scanning microscopy, permeation

\section{Introduction}

Skin is regarded as the largest organ of the human body. From a pharmaceutical point of view, it offers advantages over other routes of administration, including avoidance of the first-pass metabolism, smaller fluctuations in plasma drug levels for repeated administration, and good patient compliance. ${ }^{1}$ However, transdermal delivery is a challenging process for the drug molecule to exert its therapeutic action due to complex skin features. Skin is a multilayered organ consisting of many histological layers described as epidermis, dermis, and adipose tissue. The stratum corneum (SC) is the upper most layer of the epidermis with a thickness of 10-15 $\mu \mathrm{m}$ and represents the main barrier to drug flux. ${ }^{2}$ The physicochemical properties of the drugs are highly decisive for their ability to pass the $\mathrm{SC}$, and to permeate across the $\mathrm{SC}$, it is required that the drugs have a molecular weight less than $500 \mathrm{~g} / \mathrm{mol}$ and a $\log P$-value of $1-3$. $^{3}$ 
Olmesartan medoxomil (OLM) belongs to Biopharmaceutics Classification System class II with a limited oral bioavailability of $26 \%$ due to its poor solubility and extensive first-pass metabolism. OLM is bioactivated by ester hydrolysis to form the active olmesartan during absorption. The efficacy of OLM has been shown to be much higher or at least equivalent to many other prescribed antihypertensive agents. ${ }^{4}$ An alternative technique to oral delivery of OLM is to integrate the drug into submicroscopic vesicles and give it through transdermal route, thereby obscuring the drug molecule and delivering it to systemic circulation in a controlled manner which subsequently avoids the first-pass metabolism.

Liposomes are defined as phospholipid (PC) vesicles consisting of one or more lipid bilayers enclosing aqueous compartment. Although few studies have suggested the possibility of transdermal drug delivery using liposomes, a large number of studies rather associate liposomes with topical drug delivery. ${ }^{5}$ A new class of liposomes named transferosomes (TFs) were introduced by Cevc et $\mathrm{al}^{6}$ as a drug delivery vehicle composed of a PC bilayer and surfactant (SAA). The presence of SAA imparts elasticity to the prepared vesicles which minimizes their rupture especially when applied to the skin. TFs contain both hydrophobic and hydrophilic entities which can enclose drug molecules with a wide range of solubility. They can deform and pass through the narrow constriction (from 5 to 10 times less than their own diameter) without measurable loss. This high deformability offers better penetration of vesicles. In addition, SAA presents in the vesicles can disrupt the packing of lipids and proteins within the SC. ${ }^{7}$ Numerous reports have shown that transdermal drug delivery from TFs was more effective than that from rigid liposomes. Nevertheless, several studies showed that TFs were not able to penetrate the lower layers of SC. Ethosomes, on the other hand, which were developed by Touito et al, ${ }^{8}$ are composed of PC and ethanol. Ethosomes enhance the skin permeation of drugs due to the interdigitating effect of ethanol on the lipid bilayer of vesicles and by increasing the fluidity of SC lipids. ${ }^{9}$ Further, many attempts have been made for formulating transethosomes (TEs), containing both ethanol and SAA, which mimic the properties of both TFs and ethosomes..$^{10}$ TEs are able to cross intact skin by transcutaneous hydration gradient. Drying and partial dehydration of vesicles are considered to be the initial events in skin permeation by the vesicles after topical application. As a result, the vesicles become compressed or curved. The PC component of the vesicles has a tendency to evade a dry environment. Thus, to stay fully swollen, the vesicles follow the local hydration gradient and penetrate more strongly the hydrated layers of skin, reaching the epidermis and dermis. ${ }^{11}$
Few studies have investigated the transdermal delivery of OLM. ${ }^{12,13}$ To the best of our knowledge, there is no published research about the use of TEs to enhance the transdermal delivery of OLM. Therefore, the aim of the present work was to evaluate the ability of TEs to enhance the transdermal permeability of OLM and investigate its safety. In addition, we wanted to evaluate the antihypertensive activity of OLM-loaded TEs and estimate the amount of OLM deposited in the skin of experimental animals. For this purpose, different variables influencing vesicles' characteristics were studied employing $5^{1} \cdot 3^{1}$ full factorial design using Design Expert $^{\circledR}$ software to identify the optimum formula. SAA type $\left(\mathrm{X}_{1}\right)$ and PC:SAA ratio $\left(\mathrm{X}_{2}\right)$ were studied as independent variables, while entrapment efficiency percentage $\left(\mathrm{EE} \%\right.$; $\left.\mathrm{Y}_{1}\right)$, particle size $\left(\mathrm{PS} ; \mathrm{Y}_{2}\right)$, polydispersity index $\left(\mathrm{PDI} ; \mathrm{Y}_{3}\right)$, zeta potential $\left(\mathrm{ZP} ; \mathrm{Y}_{4}\right)$, and the amount of drug released after 6 hours $\left(\mathrm{Q} 6 \mathrm{~h} ; \mathrm{Y}_{5}\right)$ were selected as dependent variables. The optimum TEs were evaluated for morphology and stability and compared to TFs in terms of elasticity and ex vivo permeation. Confocal laser scanning microscopy (CLSM) was employed to visualize the permeation of the optimum TEs through skin layers. Further, histopathological, pharmacodynamic, and dermatokinetic studies of OLM released from the optimum TEs were conducted in male Wistar rats.

\section{Materials}

OLM was gifted by FAP Pharmaceutical Co. (Cairo, Egypt). L- $\alpha$ phosphotidylcholine from egg yolk, Span 20 (S20), Span 60 (S60), sodium deoxycholate (SDC), cellulose membrane (12,000-14,000 molecular weight cutoff), and fluorescein diacetate (FDA) were purchased from Sigma Aldrich Chemical Co. (St Louis, MO, USA). Tween 20 (T20), Tween 80 (T80), potassium dihydrogen phosphate, and dipotassium hydrogen phosphate were obtained from El-Nasr Pharmaceutical Chemicals Co. (Cairo, Egypt). Ethanol 95\%, chloroform, methanol, acetonitrile, and triethylamine (HPLC grade) were provided by Merck (Darmstadt, Germany). Angiosartan ${ }^{\circledR} 10 \mathrm{mg}$ oral tablet, indicated in the manuscript as market tablet, was purchased from Chemipharm (Cairo, Egypt).

\section{Methods}

\section{Preparation of OLM-loaded TEs}

Vesicles were prepared using three different amounts of several SAAs, namely T20, T80, S20, S60, and $\operatorname{SDC}(5,15$, and $25 \mathrm{mg})$, and PC (75, 85, and $95 \mathrm{mg})$ adopting thin-film hydration method. ${ }^{14}$ First, PC and SAA with OLM (25 mg) were weighed in a long-necked round-bottom flask and 
dissolved in $10 \mathrm{~mL}$ chloroform. By maintaining pressure under vacuum for 30 minutes, the organic phase was slowly evaporated at $60^{\circ} \mathrm{C}$ using a rotary evaporator (Rotavapor VV 2000; Heidolph, Schwabach, Germany) at $90 \mathrm{rpm}$ till a thin clear film of vesicles was formed. The film was hydrated using $10 \mathrm{~mL}$ distilled water containing $4 \%$ (v/v) ethanol, at $60^{\circ} \mathrm{C}$ which is above the lipid phase transition temperature (Tc). ${ }^{15}$ To ensure complete hydration of the film, glass beads were added and kept for 45 minutes. ${ }^{16}$ The vesicles dispersion was left overnight at $4{ }^{\circ} \mathrm{C}$ to obtain mature vesicles. For the purpose of comparison, OLM-loaded TFs (composed of $85 \mathrm{mg}$ PC and $15 \mathrm{mg}$ SDC) were prepared by the previously described method, except that in hydration step the film was hydrated with $10 \mathrm{~mL}$ distilled water.

\section{Characterization and optimization of OLM-loaded TEs Determination of EE\%}

The vesicular dispersion of the prepared formulae was centrifuged at 20,000 rpm for 1 hour at $4^{\circ} \mathrm{C}$ using a cooling centrifuge (Sigma 3-30 KS; Sigma Laborzentrifugen $\mathrm{GmbH}$, Osterode am Harz, Germany). Then, the sediment was lysed using methanol and analyzed at $\lambda_{\text {max }} 257 \mathrm{~nm}^{13}$ using a UV-Vis spectrophotometer (Shimadzu UV1650 Spectrophotometer; Shimadzu Corp., Kyoto, Japan). EE\% was determined by using the following equation: ${ }^{17}$

$$
\mathrm{EE} \%=\left(\frac{\mathrm{ED}}{\mathrm{TD}}\right) \times 100
$$

where ED is the entrapped drug concentration and TD is the total drug concentration. All measurements were performed in triplicate.

\section{Determination of PS, PDI, and ZP}

The mean PS, PDI, and ZP of vesicles dispersions were determined for the prepared formulae using Malvern Zetasizer 2000 (Malvern Instruments Ltd., Malvern, UK). The measurements were performed after dilution. ${ }^{18}$ The ZP evaluation was carried out by monitoring the electrophoretic movement of the particles in the electrical field. All measurements were performed in triplicate.

\section{Determination of Q6h}

Q6h was determined using the United States Pharmacopeia (USP) dissolution apparatus (Pharma Test, Hainburg, Germany) for 6 hours at $37^{\circ} \mathrm{C}$. Samples of $2 \mathrm{~mL}$ (containing $5 \mathrm{mg}$ OLM) from the prepared formulae were placed in plastic cylindrical tubes which have a permeation area of $3.14 \mathrm{~cm}^{2}$ with one end tightly covered with a cellulose membrane and the other end attached to the shaft of the USP dissolution apparatus instead of the baskets. The formulae were immersed in $50 \mathrm{~mL}$ PBS ( $\mathrm{pH} 7.4$ ) and ethanol mixture $(30: 20, \mathrm{v} / \mathrm{v}) .{ }^{19}$ The sink condition was maintained in this volume. Aliquots were withdrawn at 1, 2, 3, 4, 5, and 6 hours. OLM in aliquots was analyzed by a UV spectrophotometer at $\lambda_{\max } 257 \mathrm{~nm}$. The experiment was performed in triplicate.

Assessment of the influence of different formulation parameters using $5^{\prime} \cdot 3^{\prime}$ full factorial design

A complete $5^{1} .3^{1}$ full factorial design was used to detect the influence of different variables on the aspects of OLMloaded TE dispersions using minimum experimental runs. In the selected design, two factors were evaluated: one with five levels $\left(\mathrm{X}_{1}\right.$ : SAA type) and another with three levels $\left(\mathrm{X}_{2}\right.$ : PC:SAA ratio). The EE\% ( $\left.\mathrm{Y}_{1}\right)$, PS $\left(\mathrm{Y}_{2}\right), \mathrm{PDI}\left(\mathrm{Y}_{3}\right), \mathrm{ZP}\left(\mathrm{Y}_{4}\right)$, and Q6h $\left(\mathrm{Y}_{5}\right)$ were designated as dependent variables (Table 1). The experimental trials were performed with all possible combinations for preparing OLM-loaded TEs (Table 2). Design Expert software version 11 (Stat Ease, Inc., Minneapolis, MN, USA) was used to analyze experimental results to source independently the main effects of these factors followed by ANOVA to determine the significance of each factor.

\section{Optimization of OLM-loaded TEs}

For determining the optimum formula to be used for further investigations, the desirability function that predicts the optimum levels of investigated factors was calculated. The criterion set for selecting the optimum formula was achieving the least PS and PDI and the highest EE\%, ZP (as absolute value), and Q6h.

Table I Full factorial design $\left(5^{\prime} \cdot 3^{\prime}\right)$ used for optimization of TE formulations

\begin{tabular}{|l|l|}
\hline Factors (independent variables) & Levels \\
\hline $\mathrm{X}_{1}:$ SAA type & T20, T80, S20, S60, SDC \\
\hline $\mathrm{X}_{2}:$ PC:SAA ratio $(\mathrm{w} / \mathrm{w})$ & $95: 5,85: \mathrm{I5}, 75: 25$ \\
\hline Responses (dependent variables) & Desirability constraints \\
\hline $\mathrm{Y}_{1}: \mathrm{EE} \%$ & Maximize \\
\hline $\mathrm{Y}_{2}: \mathrm{PS}(\mathrm{nm})$ & Minimize \\
\hline $\mathrm{Y}_{3}: \mathrm{PDI}$ & Minimize \\
\hline $\mathrm{Y}_{4}: \mathrm{ZP}(\mathrm{mV})$ & Maximize (as absolute value) \\
\hline $\mathrm{Y}_{5}: \mathrm{Q} 6 \mathrm{~h}(\%)$ & Maximize \\
\hline
\end{tabular}

Abbreviations: EE\%, entrapment efficiency percentage; PC, phospholipid; PDI, polydispersity index; PS, particle size; Q6h, amount of drug released after 6 hours; S20, Span 20; S60, Span 60; SAA, surfactant; SDC, sodium deoxycholate; T20, Tween 20; T80, Tween 80; TE, transethosome; ZP, zeta potential. 
Table 2 Experimental runs, independent variables, and measured response of the $5^{\prime} .3^{\prime}$ full factorial experimental design of OLMloaded TEs

\begin{tabular}{|c|c|c|c|c|c|c|c|}
\hline \multirow[t]{2}{*}{ TE formulation } & $x_{1}$ & $x_{2}$ & $\mathbf{Y}_{1}$ & $\mathbf{Y}_{2}$ & $\mathbf{Y}_{3}$ & $\mathbf{Y}_{4}$ & $\mathbf{Y}_{5}$ \\
\hline & SAA type & $\begin{array}{l}\text { PC:SAA } \\
\text { ratio }(w / w)\end{array}$ & EE\% & PS (nm) & PDI & ZP (mV) & Q6h (\%) \\
\hline TEI & T20 & 95:5 & $78.91 \pm 2.52$ & $324.63 \pm 1.26$ & $0.14 \pm 0.02$ & $-22.80 \pm 0.26$ & $43.18 \pm 0.94$ \\
\hline TE2 & T20 & $85: 15$ & $72.32 \pm 0.59$ & $288.81 \pm 5.49$ & $0.13 \pm 0.06$ & $-11.31 \pm 0.37$ & $44.00 \pm 0.21$ \\
\hline TE3 & T20 & $75: 25$ & $63.20 \pm 1.15$ & $285.44 \pm 2.89$ & $0.14 \pm 0.08$ & $-|0.2| \pm 0.83$ & $56.83 \pm 0.48$ \\
\hline TE4 & T80 & 95 & $79.7 I \pm 2.00$ & $380.00 \pm 6.00$ & $0.11 \pm 0.20$ & $-16.00 \pm 0.74$ & $40.85 \pm 1.50$ \\
\hline TE5 & T80 & $85: 15$ & $74.42 \pm 1.26$ & $363.75 \pm 7.50$ & $0.22 \pm 0.09$ & $-|5.8| \pm 0.5 \mid$ & $42.48 \pm 0.58$ \\
\hline TE6 & T80 & $75: 25$ & $68.00 \pm 1.46$ & $316.84 \pm 7.64$ & $0.06 \pm 0.07$ & $-9.00 \pm 1.08$ & $53.93 \pm 0.24$ \\
\hline TE7 & S20 & $95: 5$ & $81.80 \pm 4.63$ & $394.95 \pm 1.80$ & $0.05 \pm 0.01$ & $-30.21 \pm 0.99$ & $37.98 \pm 0.30$ \\
\hline TE8 & $S 20$ & $85: 15$ & $75.00 \pm 1.64$ & $366.7 I \pm 22.58$ & $0.04 \pm 0.02$ & $-19.80 \pm 3.14$ & $40.64 \pm 0.39$ \\
\hline TE9 & S20 & $75: 25$ & $67.20 \pm 1.01$ & $329.4 I \pm 2.8 I$ & $0.24 \pm 0.18$ & $-16.50 \pm 0.29$ & $43.64 \pm 1.20$ \\
\hline TEIO & 560 & \begin{tabular}{|l|}
$95: 5$ \\
\end{tabular} & $91.90 \pm 2.25$ & $442.89 \pm 17.64$ & $0.09 \pm 0.10$ & $-28.50 \pm 0.34$ & $33.95 \pm 0.48$ \\
\hline TEII & 560 & $85: 15$ & $83.50 \pm 3.26$ & $419.35 \pm 21.03$ & $0.14 \pm 0.03$ & $-17.72 \pm 2.80$ & $38.73 \pm 3.80$ \\
\hline TEI2 & $S 60$ & $75: 25$ & $71.20 \pm 5.35$ & $372.10 \pm 19.80$ & $0.12 \pm 0.15$ & $-14.9 \mid \pm 3.85$ & $39.48 \pm 2.50$ \\
\hline TEI3 & SDC & $95: 5$ & $66.50 \pm 1.25$ & $283.90 \pm 18.70$ & $0.20 \pm 0.12$ & $-35.7 \mathrm{I} \pm \mathrm{I} .63$ & $64.36 \pm 2.30$ \\
\hline TEI4 & SDC & $85: 15$ & $58.54 \pm 1.30$ & $222.60 \pm 2.59$ & $0.11 \pm 0.06$ & $-20.8 \mathrm{I} \pm 0.34$ & $67.44 \pm 0.25$ \\
\hline TEI5 & SDC & $75: 25$ & $48.13 \pm 0.80$ & $168.11 \pm 1.39$ & $0.13 \pm 0.04$ & $-17.82 \pm 0.88$ & $69.68 \pm 3.00$ \\
\hline
\end{tabular}

Note: Data represented as mean \pm SD $(n=3)$.

Abbreviations: EE\%, entrapment efficiency percentage; OLM, olmesartan medoxomil; PC, phospholipid; PDI, polydispersity index; PS, particle size; Q6h, amount of drug released after 6 hours; S20, Span 20; S60, Span 60; SAA, surfactant; SDC, sodium deoxycholate; T20, Tween 20; T80, Tween 80; TE, transethosome; ZP, zeta potential.

\section{Transmission electron microscopy (TEM)}

Morphology of the optimum TEs was examined using a transmission electron microscope (JEOL JEM 1230; JEOL, Tokyo, Japan). The vesicular dispersion was placed in the form of a thin film on a carbon-coated copper grid, stained using phosphotungstic acid $1.5 \%$, and then viewed and photographed. ${ }^{17}$

\section{Differential scanning calorimetry (DSC)}

The thermal analysis of pure OLM, PC, SDC, physical mixture of OLM and transethosomal components, and the optimum TEs was performed using a differential scanning calorimeter (DSC-60; Shimadzu Corp.) calibrated with purified indium. Approximately $5 \mathrm{mg}$ of each sample was mounted in a standard aluminum pan and heated at a temperature range of $10^{\circ} \mathrm{C}-250^{\circ} \mathrm{C}$ at a scanning rate of $5^{\circ} \mathrm{C} / \mathrm{min}$ under inert nitrogen flow $(25 \mathrm{~mL} / \mathrm{min}) .{ }^{18}$

\section{Stability studies}

Optimum TEs were stored at $4{ }^{\circ} \mathrm{C}$ and $25^{\circ} \mathrm{C}$ for 45 days. Samples were withdrawn at 0 and 45 days. Stability was evaluated by comparing the initial measurements with results obtained after storage..$^{20}$ The EE\%, PS, PDI, ZP, and Q6h of the vesicles were measured as described previously.
Vesicles were examined visually for aggregation and change in their appearance. Statistical significance was analyzed by Student's $t$-test using SPSS ${ }^{\circledR}$ software 22.0. Difference at $P \leq 0.05$ was considered significant.

\section{Measurement of vesicles' elasticity}

Extrusion method was used for comparative assessment of elasticity of the bilayer for the prepared TFs and optimum TEs. Vesicles were extruded through a nylon filter with a diameter of $200 \mathrm{~nm}$ at 2.5 bar (Büchi Labortechnik AG, Flawil, Switzerland). Elasticity was expressed in terms of deformability index (DI) according to the following equation: ${ }^{21}$

$$
\mathrm{DI}=J\left(\frac{r v}{r p}\right)^{2}
$$

where $J$ is the weight of dispersion extruded in 10 minutes, $r v$ is the size of vesicles after extrusion (nm), and $r p$ is the pore size of the barrier $(\mathrm{nm})$. Statistical significance was analyzed by Student's $t$-test using SPSS software 22.0. Difference at $P \leq 0.05$ was considered significant. The experiment was performed in triplicate. 


\section{Ex vivo studies}

Comparative study between ex vivo permeation through rat skin and shed snake skin

The transdermal permeability of OLM suspension, the prepared TFs, and optimum TEs through rat skin and shed snake skin was studied. Rat skin was excised from animals after being sacrificed. Shed snake skin was donated by Giza Zoo, Giza, Egypt. The setting of the test was similar to that used for the in vitro release, but the cellulose membrane was replaced by dorsal skin with the SC facing the donor compartment. ${ }^{21}$ Aliquots were taken from the receiving compartment at time intervals of 2, 4, 8, 10, and 12 hours. Each sample was analyzed using HPLC. The studies were performed in triplicates, and the results were expressed as mean values $\pm \mathrm{SD}$. The permeation flux $\left(\mathrm{J}_{\max }\right)$ at 12 hours and the enhancement ratio (ER) were calculated according to the following equations: 22

$$
\begin{gathered}
\mathrm{J}_{\text {max }}=\frac{\text { Amount of drug permeated }}{\text { Time } \times \text { Area of membrane }} \\
\text { ER }=\frac{\mathrm{J}_{\text {max }} \text { of the nanovesicles }}{\mathrm{J}_{\text {max }} \text { of the drug suspension (control) }}
\end{gathered}
$$

Statistical significance was analyzed by one-way ANOVA using SPSS software 22.0. Post hoc analysis was performed using Tukey's honestly significant difference (HSD) test. Difference at $P \leq 0.05$ was considered significant.

\section{HPLC determination of OLM}

An isocratic reversed-phase validated HPLC method was used for detection and quantification of OLM. ${ }^{4}$ The apparatus used was an Agilent 1260 infinity LC system equipped with a quaternary pump, an auto-sampler unit, and a UV detector (Shimadzu Corp.). The stationary phase was Thermo ${ }^{\circledR} \mathrm{C}_{18}(150 \times 4.6 \mathrm{~mm})$ column packed with a $5 \mu \mathrm{m}$ size adsorbent. The mobile phase was composed of deionized water:triethylamine:acetonitrile $(60: 0.3: 40, \mathrm{v} / \mathrm{v} / \mathrm{v})$, and the $\mathrm{pH}$ was adjusted to 6.3 with $18 \%$ phosphoric acid. The flow rate was set at $1 \mathrm{~mL} / \mathrm{min}$, and the detector was set at $\lambda_{\max }$ $257 \mathrm{~nm}$. Injection volume was $20 \mu \mathrm{L}$. The retention time of OLM was 3 minutes.

\section{Ex vivo visualization using CLSM study}

FDA-loaded TEs were formulated using the same method used for preparing the optimum TEs, but FDA at a concentration of $1 \%$ substituted OLM in the optimum formula.
To simulate the application of TEs onto the skin surface, FDA-loaded TEs were applied on skin surface and allowed to remain for 6 hours. Dorsal rat skin was mounted with the SC facing the donor compartment in diffusion cells with the same setting used in the ex vivo permeation study. After that, the skin was rinsed with $10 \%$ ethanol. Longitudinal skin sections that were treated with vesicles and 1\% FDA solution as a control were kept in paraffin wax and cut into sections using a microtome blade to compare and observe the distribution of vesicles in the skin layers. ${ }^{23}$ The sample slides were examined using an inverted microscope (LSM 710; Carl Zeiss, Oberkochen, Germany). The excitation and emission wavelengths of FDA were $\lambda_{\max } 497 \mathrm{~nm}$ and $\lambda_{\text {max }} 516 \mathrm{~nm}$, respectively. The skin thickness was optically scanned under a $\times 40$ objective lens (EC-Plan Neofluar $63 \mathrm{x} / 01.40$ Oil DICM27). Confocal images were taken and processed by means of LSM Image Browser software, release 4.2 (Carl Zeiss Microimaging GmbH, Jena, Germany).

\section{In vivo studies}

Eighty-seven male Wistar rats, weighing 150-200 g, with an average age of 7 weeks were used in the in vivo studies. The study design was approved by the ethical committee of the Faculty of Pharmacy, Cairo University (reference number $=(\mathrm{PI})$ 1867). The use and handling of animals in all studies complied with the EU directive 2010/63/EU for animal experiment. The animals were kept in cages at a temperature of $22^{\circ} \mathrm{C}$ and relative humidity of $55 \%$. Water and rodents chow were provided. The animals were kept in a dark:light cycle of 12 hours each. Rats were left for 7 days for adaptation before experiments. Nine animals were used in the histopathological study, 24 in the pharmacodynamic study, and 54 in the dermatokinetic study. For the administration of OLM suspension and optimum TEs in the in vivo studies, bottle caps were utilized which acted as drug pools with an area of $4.91 \mathrm{~cm}^{2}$. The bottle caps were fixed to dorsal rat skin which was shaved with an electric clipper 24 hours before application of the samples. Moreover, the samples were added nonocclusively into the drug pools. ${ }^{24-26}$

\section{Histopathological study}

Nine male Wistar rats were divided into three groups of three rats each. The treatment period was 1 day. Group I served as control, while groups II and III received OLM suspension and optimum TEs topically, respectively. Skin samples were fixed in $10 \%$ formol saline for 24 hours, followed by washing and dehydration using alcohol. Specimens were cleared in 
xylene and embedded in paraffin wax blocks and kept at $56^{\circ} \mathrm{C}$ for another 24 hours, followed by sectioning as paraffin bees wax tissue blocks at $4 \mathrm{~mm}$ by a sledge microtome (Rotary Leica RM2245; Leica Biosystems, Wetzlar, Germany). The specimens were deparaffinized and stained by H\&E stains for histopathological examination using a light microscope (Axiostar Plus; ZEISS, Oberkochen, Germany). ${ }^{24}$

\section{Pharmacodynamic study}

Pharmacodynamic study was carried out using animal tail noninvasive blood pressure (BP) system (NIBP 200 A; Biopac System, Inc., Goleta, CA, USA) based on cuff tail technique. Twenty-four male Wistar rats were divided into four groups (groups A-D) of six animals each. Group A was taken as a negative control. Hypertension was induced in the remaining groups (groups B-D) by subcutaneous injection of methyl prednisolone acetate (MPA; DepoMedrol $^{\circledR}$; Pfizer, New York, NY, USA) (20 mg/kg/week) for 2 weeks. Group B served as hypertensive positive control and received no further treatment. Group $\mathrm{C}$ received market tablet (Angiosartan $10 \mathrm{mg}$ ) orally that was previously crushed and administered to the rats by using oral gavage. ${ }^{27}$ Group D was subjected to transdermal treatment with $4 \mathrm{~mL}$ of optimum TEs (containing $10 \mathrm{mg}$ OLM). The rats were then placed in the restrainer, and the BP in the tail was recorded at predetermined time intervals at $0,1,2,4$, 6,8 , and 24 hours. ${ }^{28}$ Statistical significance was analyzed by one-way ANOVA using SPSS software 22.0. Post hoc analysis was performed using Tukey's HSD test. Difference at $P \leq 0.05$ was considered significant. Percentage of reduction in BP from hypertensive control was calculated by the following equation:

$$
\begin{aligned}
& \text { Percentage of reduction in } \mathrm{BP}= \\
& \mathrm{BP} \text { of hypertensive positive control } \\
& \frac{-\mathrm{BP} \text { of treated group }}{\mathrm{BP} \text { of hypertensive positive control }} \times 100
\end{aligned}
$$

\section{Dermatokinetic study}

Dermatokinetic study was done using 54 male Wistar rats which were divided into three groups of 18 animals each. Group I acted as control, while groups II and III received OLM suspension and optimum TEs topically, respectively. Half milliliter of each sample (OLM suspension and optimum TEs) was applied to dorsal rat skin on an area of $4.91 \mathrm{~cm}^{2}$, which was shaved 24 hours before application, as previously mentioned. After treatment, three animals from each group were sacrificed at different time intervals (1, 2, 4, 6, 8 , and 10 hours). The excised skin was cut into pieces and sonicated in $5 \mathrm{~mL}$ methanol for 30 minutes. The extract was then filtered through a $0.45 \mu \mathrm{m}$ filter, and the concentration of OLM was determined by HPLC. The destruction of animal carcasses was achieved by incineration. ${ }^{24-26}$ Dermatokinetic parameters such as $\mathrm{T}_{\max }, \mathrm{C}_{\max }$, and $\mathrm{AUC}_{0-10}$ were determined by employing Kinetica ${ }^{\circledR} 5$ software (Thermo Fisher Scientific Inc., Waltham, MA, USA). $\mathrm{C}_{\max }$ and $\mathrm{AUC}_{0-10}$ were compared between the two treatments using ANOVA test. In addition, nonparametric signed-rank test (Mann-Whitney's test) was employed for the comparison of medians of $\mathrm{T}_{\text {max }}$ for the treatments using SPSS software 22.0. Difference at $P \leq 0.05$ was considered significant.

\section{Results and discussion Analysis of factorial design}

Preliminary trials were performed (data not shown) to determine the effective ranges of the independent variables. Two independent variables were studied: the SAA type $\left(\mathrm{X}_{1}\right)$ and PC:SAA ratio $\left(\mathrm{X}_{2}\right)$. EE\% $\left(\mathrm{Y}_{1}\right)$, PS $\left(\mathrm{Y}_{2}\right)$, PDI $\left(\mathrm{Y}_{3}\right), \mathrm{ZP}\left(\mathrm{Y}_{4}\right)$, and Q6h $\left(\mathrm{Y}_{5}\right)$ were selected as dependent variables. Referring to the design analysis results in Table 3, the model selected was two-factor interaction and it was noted that the predicted $R^{2}$ values were in reasonable agreement with the adjusted $R^{2}$ in all responses except PDI. The negative predicted $R^{2}$ value of PDI implies that the overall mean is a better predictor of the response. ${ }^{29}$ This might be due to that PDI of the prepared

\begin{tabular}{|c|c|c|c|c|c|}
\hline Responses & EE\% & PS (nm) & PDI & ZP $(\mathbf{m V})$ & Q6h (\%) \\
\hline Adequate precision & 58.87 & 43.81 & 4.31 & 31.76 & 39.83 \\
\hline Adjusted $R^{2}$ & 0.99 & 0.98 & 0.25 & 0.97 & 0.98 \\
\hline Predicted $R^{2}$ & 0.98 & 0.96 & -0.53 & 0.95 & 0.97 \\
\hline Significant factors & $X_{1}, X_{2}$ & $X_{1}, X_{2}$ & - & $x_{1}, x_{2}$ & $X_{1}, X_{2}$ \\
\hline Predicted value of optimum formula (TEI4) & 59.17 & 223.59 & 0.10 & -20.57 & 67.72 \\
\hline Observed value of optimum formula (TEI4) & 58.54 & 222.60 & 0.11 & -20.81 & 67.44 \\
\hline
\end{tabular}

Table 3 Output data of the $5^{1} \cdot 3^{\prime}$ full factorial analysis of TE formulations and predicted and observed values for the optimum TE formula (TEI4)

Abbreviations: EE\%, entrapment efficiency percentage; PDI, polydispersity index; PS, particle size; Q6h, amount of drug released after 6 hours; TE, transethosome; ZP, zeta potential. 
TEs was not affected by the studied factors. The adequate precision with a ratio greater than 4 is desirable which was observed in all responses as shown in Table 3.

\section{The effect of formulation variables on $\mathrm{EE} \%$}

Encapsulation of drugs within PC formulations offers desired delivery, enhanced stability, protection, and permeability depending on lipid composition and properties. ${ }^{30}$ The effect of the independent variables, SAA type $\left(\mathrm{X}_{1}\right)$ and $\mathrm{PC}$ :SAA ratio $\left(\mathrm{X}_{2}\right)$, on the EE\% of OLM in vesicles is shown in Table 2 and is graphically illustrated as three-dimensional (3-D) surface plots in Figure 1A. SAA type $\left(\mathrm{X}_{1}\right)$ had a significant effect on $\mathrm{EE} \%(P<0.0001)$. The $\mathrm{EE} \%$ for formulae containing $\mathrm{S} 60$ was higher compared to other formulations. This is in accordance with the results obtained by Aboud et $\mathrm{al}^{31}$ and could be explained on the basis of hydrophilic-lipophilic balance (HLB) values of the SAAs which were 4.7, 8.6, 15, 16.7, and 23.4 for S60, S20, T80, T20, and SDC, respectively. ${ }^{31,32}$ It is well known that SAAs with lower HLB values are more lipophilic and would favor the entrapment of lipophilic drug. ${ }^{26}$ This explains the increased EE\% of OLM, which is a highly lipophilic drug with a $\log P$-value of 5.6, ${ }^{33}$ in formulae containing S60. Furthermore, the highly hydrophobic alkyl chains of S60 interact with the hydrophobic domain of the vesicles leading to more condensed layers and thus prevent drug leaching from vesicles. ${ }^{34}$ On the other hand, SAAs with increased hydrophilicity like SDC form less rigid vesicles due to larger polar head groups and also increase drug solubilization in the aqueous medium during preparation which would lower the EE\% of OLM ${ }^{35}$ In addition, the higher EE\% values of S60 compared to S20 might be related to the Tc of the SAA that could be an important factor in explaining the effects of SAA on EE\% of lipid-based vesicles. The Tc of $\mathrm{S} 60$ and $\mathrm{S} 20$ is $53^{\circ} \mathrm{C}$ and $16^{\circ} \mathrm{C}$, respectively. ${ }^{36}$ It was reported that the higher the Tc of SAA, the better is its ability to form a more ordered structure and a less leaky bilayer which may further improve the EE\%. On the other hand, SAAs with lower Tc may result in irregular structural formation and increase the fluidity of the vesicles' bilayers that in turn reduces the drug $\mathrm{EE} \%{ }^{37}$
A
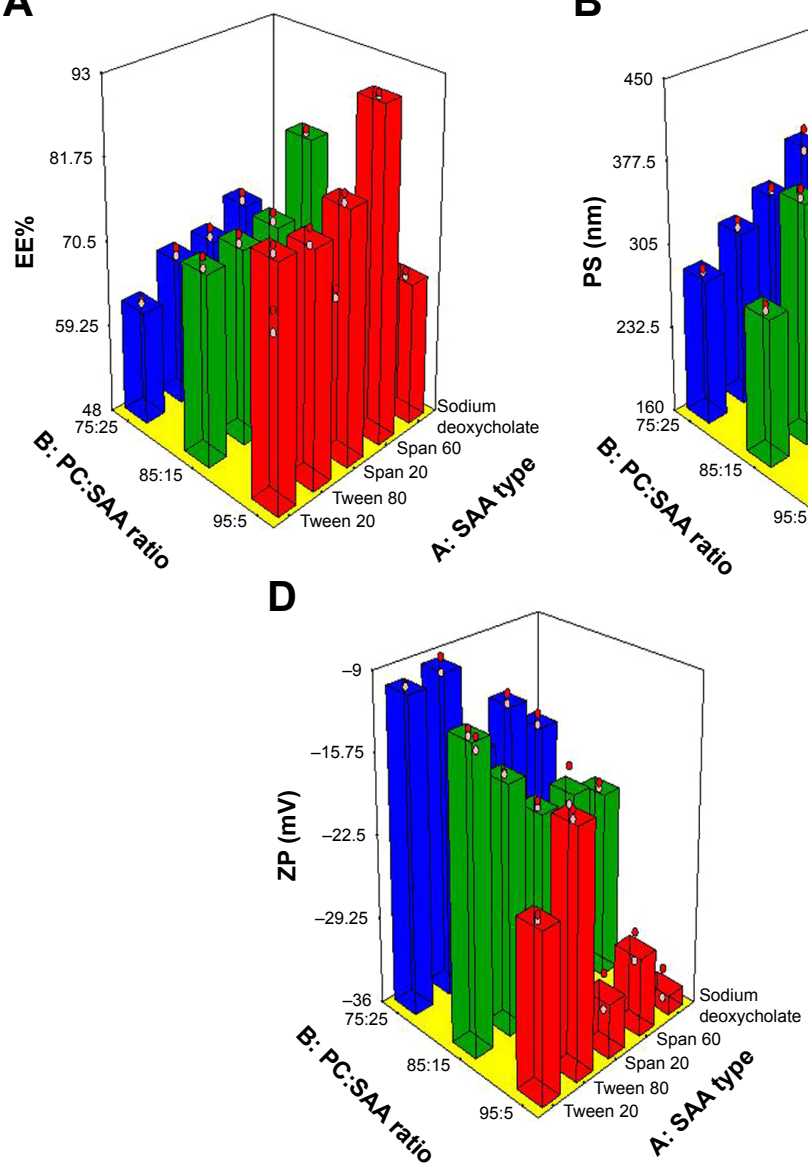

B

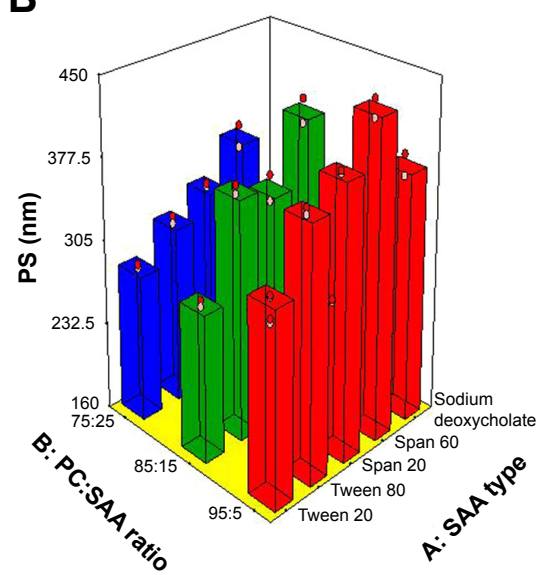

C

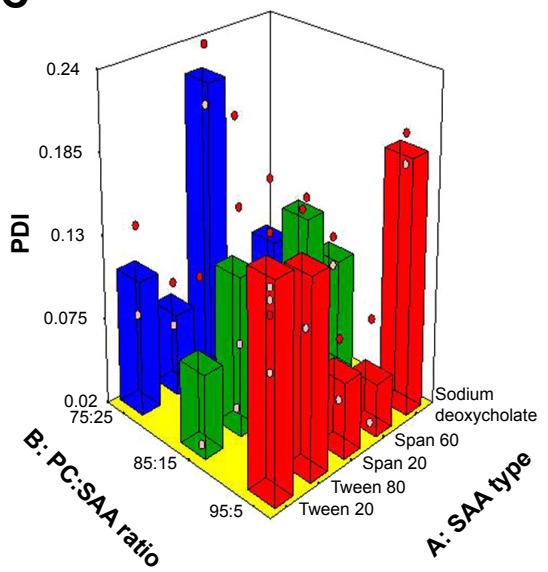

E

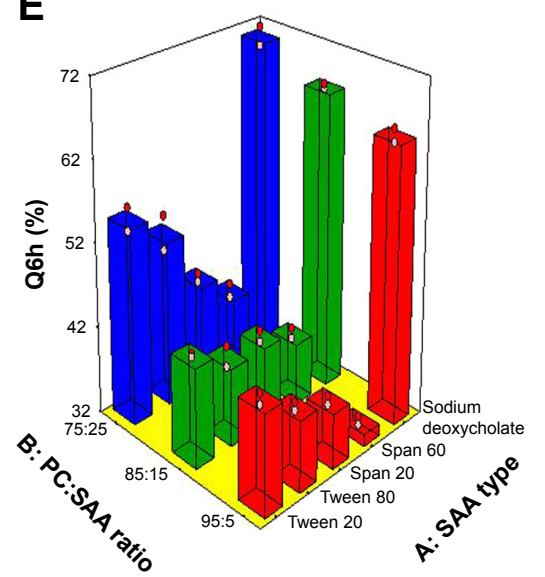

Figure I Response 3-D plots for the effect of SAA type $\left(X_{1}\right)$ and PC:SAA ratio $\left(X_{2}\right)$ on $(\mathbf{A})$ EE\%, (B) PS, (C) PDI, (D) ZP, and (E) Q6h of OLM-loaded TEs.

Abbreviations: 3-D, three-dimensional; EE\%, entrapment efficiency percentage; OLM, olmesartan medoxomil; PC, phospholipid; PDI, polydispersity index; PS, particle size; Q6h, amount of drug released after 6 hours; SAA, surfactant; TEs, transethosomes; ZP, zeta potential. 
PC:SAA ratio $\left(\mathrm{X}_{2}\right)$ also had a significant effect on $\mathrm{EE} \%$ $(P<0.0001)$. PC:SAA ratio of 95:5 showed the highest EE\%, while changing the ratio to 75:25 lowered significantly the drug EE\% which was irrespective of the SAA type. The results were in accordance with Ezzat et $\mathrm{al}^{38}$ who reported that EE\% decreased as PC amount decreased which could be attributed to the decrease in the space available for drug loading into the vesicles. ${ }^{39}$

\section{The effect of formulation variables on PS}

The z-average diameter representing the mean hydrodynamic diameter of the particles ${ }^{40}$ was measured, and is presented in Table 2 and graphically illustrated in 3-D surface plots (Figure 1B). It is noticeable that both SAA type $\left(\mathrm{X}_{1}\right)$ and PC:SAA ratio $\left(\mathrm{X}_{2}\right)$ influenced significantly $(P<0.0001)$ the PS of the vesicles. Considering the SAA type, the PS was greater for formulae prepared using S60 than the equivalent formulations prepared using other SAAs. Yeo et $\mathrm{al}^{41}$ stated that the PS of vesicles increases when HLB value of SAA decreases which is related to decrease in the hydrophilic portion of SAA. Thus, S60 with the lowest HLB value (4.7), as mentioned earlier, resulted in the highest PS. Further, the formulae prepared with S60 and T80 with an alkyl chain length of 18 carbon atoms showed larger PS when compared to their corresponding formulations prepared with S20 and T20 with an alkyl chain length of only $\mathrm{C}_{12}$, respectively. SAAs with a longer alkyl chain result in a larger core space of the vesicles with a greater diameter. ${ }^{21}$ In addition, this may be attributed to the fact that the increase in alkyl chain length would result in an increase in the value of the critical packing parameter of the SAA which determines the aggregation state of the vesicles' components. ${ }^{42}$ On the other hand, the smallest vesicles were obtained upon incorporation of anionic SDC into the vesicles' bilayers because of the steric repulsion between the charged molecules exposed from the outer layer of the vesicles' membranes. This would increase the vesicles' membranes curvature and thus lessen the size of the vesicles..$^{22}$ Furthermore, the high HLB value of SDC (23.4) also accounted for the small PS, as mentioned earlier. ${ }^{32}$

With respect to PC:SAA ratio $\left(\mathrm{X}_{2}\right)$, the PC:SAA ratio of 75:25 resulted in the smallest PS compared with the other two ratios. It is known that $\mathrm{PC}$ has a cylindrical shape because of the large volume of its hydrophobic tail. Moreover, SAA molecule has a cone-like shape because the amphiphilic head group needs more space than the cross-sectional area of the hydrophobic tail. When the cone-shaped SAAs interact with lipid bilayers, the hydrophobic tails of SAAs insert into the lipid bilayers and their head groups interact with the lipid polar fragments. Increasing the quantity of SAA increases the disparity between the hydrophobic chain lengths of PC and SAA, resulting in an increase in the curvature of lipid SAA aggregates. Consequently, the cone-shaped SAA generates perturbation to the closely packed lipid bilayers resulting in reduction of the PS. ${ }^{43}$ It was also observed from the results that the PS was in accordance with the amount of drug entrapped into the vesicles. Therefore, the decrease in EE\% would give another explanation for the lower PS of vesicles. ${ }^{44}$

\section{The effect of formulation variables on PDI}

PDI is a measure of the width of unimodal size distributions. A value of 0 indicates homogenous dispersion, while a value of 1 indicates an entirely heterogeneous polydisperse population. An acceptable PDI should have a value below 0.5..$^{26,45}$ PDI values are presented in Table 2 and graphically illustrated in 3-D surface plots (Figure 1C). Factorial analysis of variance showed that both independent variables, SAA type $\left(\mathrm{X}_{1}\right)$ and PC:SAA ratio $\left(\mathrm{X}_{2}\right)$, showed no significant effect on PDI with $P$-values of 0.78 and 0.59 , respectively. As observed from the results, the PDIs of the prepared vesicles were in general small which indicates good homogeneity and narrow size distribution.

\section{The effect of formulation variables on ZP}

Particle aggregation is less likely to occur for charged vesicles having a $\mathrm{ZP}$ of $\geq|30| \mathrm{mV}$ because of electrostatic repulsion. ${ }^{46}$ The ANOVA results showed that both independent variables, SAA type $\left(\mathrm{X}_{1}\right)$ and PC:SAA ratio $\left(\mathrm{X}_{2}\right)$, showed a significant effect on $\mathrm{ZP}(P<0.0001)$ as depicted in Table 2 and graphically illustrated as response 3 -D plots in Figure 1D. The ZP of vesicles decreased when using Tweens rather than Spans which could be attributed to the higher HLB values of Tweens compared to Spans. Kim et a ${ }^{47}$ stated that the HLB value of the SAA influences the competitive adsorption of $\mathrm{OH}$ ions at the interface which are present in the hydration medium. If the HLB value of the SAA is lower (the nonpolar interface is more), more $\mathrm{OH}$ ion adsorption will occur and consequently ZP will increase. In addition, the presence of $\left(\mathrm{CH}_{2}-\mathrm{CH}_{2}-\mathrm{O}\right)_{n}$ in Tweens formed hydrogen bonds with water molecules and resulted in lower ZP values. ${ }^{48}$ Furthermore, the addition of anionic SDC resulted in the highest ZP values compared to other SAAs. After ionization in water, SDC gets adsorbed on particle/water interface and forms an electric double layer. On the other hand, nonionic SAAs have more profound effect on extending the diffuse layer which generates lower ZP while anionic SAAs are held up more tightly around the particle and consequently have 
lesser effect on the thickness of the diffuse layer, retaining higher ZP values. ${ }^{49}$

With respect to $\mathrm{PC}: \mathrm{SAA}$ ratio $\left(\mathrm{X}_{2}\right)$, vesicles with the greatest amount of PC exhibited the highest ZP. Although PC heads are zwitterionic and thus theoretically uncharged at neutral $\mathrm{pH}$, they give rise to negative $\mathrm{ZP}$ value in water. ${ }^{50,51}$ This has been interpreted in terms of hydration layers formed around the surface and the orientation of lipid head groups. ${ }^{52}$ Makino et $\mathrm{al}^{53}$ postulated that the charge of PC bilayer is due to the direction of the dipole connecting the negative charge of phosphatidyl group and the positive charge of choline group in the head group of a lipid molecule. It was reported that in a medium of low ionic strength, the head group is oriented in such a way that the phosphatidyl group is outside with the choline group inside in the head group resulting in a negative surface charge.

\section{The effect of formulation variables on Q6h}

The release profile is an important marker used to predict the in vivo performance of the drug. It has been suggested that ethanol may provide the vesicles with soft flexible characteristics which allow easy drug diffusion through membranes. Furthermore, the presence of ethanol may decrease the hydration layer around the vesicles which facilitates the release of the drug. ${ }^{17}$ Q6h values for TEs are shown in Table 2 and graphically illustrated in 3-D surface plots (Figure 1E). The ANOVA results revealed that SAA type $\left(\mathrm{X}_{1}\right)$ had a significant effect on drug release $(P<0.0001)$. The release of OLM from TEs was in the following order: $\mathrm{SDC}>\mathrm{T} 20>\mathrm{T} 80>$ $\mathrm{S} 20>\mathrm{S} 60$. The results were in accordance with Aboud et $\mathrm{al}^{31}$ who reported that SAAs with low HLB value, long alkyl chain, and high Tc slow down the release. Moreover, Tweens as hydrophilic SAAs with high HLB value have greater solubilizing power on hydrophobic drugs compared with hydrophobic Spans with low HLB value. ${ }^{54}$ In addition, vesicles prepared with SAAs of higher Tc (Spans) are more ordered, stable, and less leaky. ${ }^{37}$ Furthermore, due to greater interaction between alkyl chains of SAA and PC in the case of SAAs with longer alkyl chain length (T80 and S60), the packing of the vesicles increases and becomes less permeable for the drug when compared with equivalent SAAs with shorter alkyl chain length (T20 and S20). ${ }^{42}$ On the other hand, the results showed that the highest Q6h values were observed for formulae containing SDC. This could be attributed to that SDC produced the smallest PS compared to other SAAs which resulted in increasing the total surface area and hence increased the release rate. ${ }^{31}$ Furthermore, the addition of SDC might have produced mixed micelles with
PC which resulted in the enhancement of aqueous solubility of OLM in aqueous phase. ${ }^{26}$

$\mathrm{PC}: \mathrm{SAA}$ ratio $\left(\mathrm{X}_{2}\right)$ showed a significant effect on $\mathrm{Q} 6 \mathrm{~h}$ $(P<0.0001)$. Q6h decreased at high PC amount (95 mg) which could be attributed to that the lipid membranes are present in a firm state which hinders drug release. ${ }^{31}$ Besides, Kriwet and Müller-Goymann ${ }^{55}$ related the decrease in drug release with increased content of PC to the high affinity of hydrophobic drug to vesicles' bilayers. On the other hand, when the amount of SAA increases, the formation of micelles within the bilayer may increase the membrane permeability and thus enhances drug release. ${ }^{56}$

\section{Selection of the optimum formula}

To select the optimum formula, certain criteria were set in Design Expert software version 11. These criteria favored particles with the highest EE\%, ZP (as absolute value), and Q6h and the lowest PS and PDI. The optimum formula was TE14 which met these criteria and composed of SDC as SAA and had a PC:SAA ratio of 85:15. TE14 showed an EE\% of $58.50 \% \pm 1.30 \%$, a PS of $222.60 \pm 2.50 \mathrm{~nm}$, a PDI of $0.11 \pm 0.06$, a ZP of $-20.80 \pm 0.30 \mathrm{mV}$, and a Q6h of $67.40 \% \pm 0.20 \%$. In order to validate the experiment, the predicted and observed responses of TE14 were compared and are shown in Table 3. A high correlation was observed between the observed and predicted values. Subsequently, TE14 was selected as the optimum formula for further investigations.

\section{Transmission electron microscopy}

The external morphology of the optimum TE formula (TE14) was studied using TEM analysis. The morphological analysis of TE14 showed that the vesicles were spherical in shape and had a uniform size distribution (Figure 2). The PS of

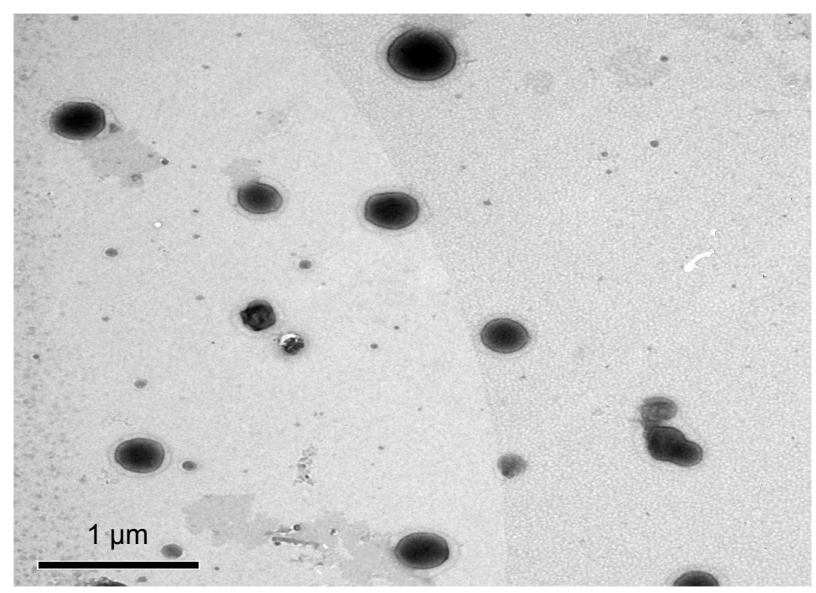

Figure 2 Transmission electron micrograph of the optimum TE formula (TEI4). Abbreviation: TE, transethosome. 
the vesicles determined by Zetasizer agreed well with TEM results.

\section{Differential scanning calorimetry}

Figure 3 shows the thermograms of pure OLM, PC, SDC, physical mixture of OLM and transethosomal components, and TE14. The DSC scan of pure OLM depicted a single endothermic peak at $184.14^{\circ} \mathrm{C} .{ }^{33}$ The DSC thermal curve of PC did not show any thermal effect in the temperature range studied. The behavior observed corresponds to a large endothermic effect which occurs within a wide interval of temperatures. ${ }^{57}$ Regarding SDC, its thermogram revealed the presence of a broad endotherm that started at $110.82^{\circ} \mathrm{C}$ probably due to the loss of water molecules followed by an exothermic recrystallization peak at $214^{\circ} \mathrm{C} .{ }^{58}$ The characteristic peak of OLM present in the thermogram of physical mixture supports that it still stayed in its crystalline nature. ${ }^{59}$ The disappearance of the characteristic peak of the drug in DSC thermogram of TE14 might indicate the entrapment of the drug in vesicles due to interactions. Such interactions probably include formation of hydrogen bonds, Van der Waal's attractive forces, or dipole-dipole forces at the hydroxyl groups of drug and both PC and SDC. These interactions

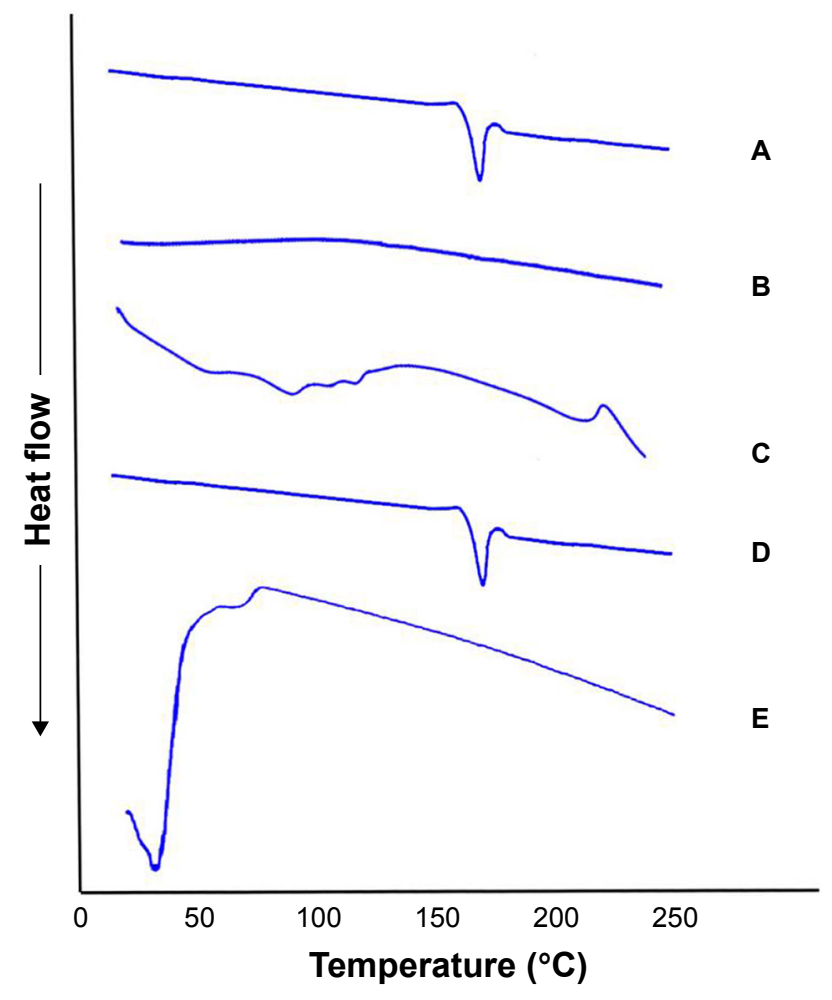

Figure 3 DSC thermogram of (A) OLM, (B) PC, (C) SDC, (D) physical mixture of OLM and transethosomal components, and (E) TEI4.

Abbreviations: DSC, differential scanning calorimetry; OLM, olmesartan medoxomil; PC, phospholipid; SDC, sodium deoxycholate; TE, transethosome. might explain the formation of favorable vesicle shape and structure with good stability. ${ }^{60}$

\section{Stability study}

Lipid vesicular formulations tend to fuse and disintegrate during storage which leads to changes in PS, PDI, and ZP. These changes also bring about drug leakage from the vesicles and reduction in the EE\%. ${ }^{20}$ Statistical analysis revealed that there was no significant difference in $\mathrm{EE} \%$, PS, PDI, and Q6h of the stored vesicles when compared to the fresh ones after 45 days at $4^{\circ} \mathrm{C}$ and $25^{\circ} \mathrm{C}$ (Table 4 ). In addition, no aggregation or change in appearance was observed after storage. These findings indicate good stability of TE14.

\section{Measurement of vesicles' elasticity}

It is well known that the elasticity of vesicles could be accomplished by incorporating SAA into the vesicles' bilayers. In the present study, TE14 contained SDC as SAA which is capable of weakening the lipid bilayers of the vesicles and consequently increases their deformability. Subsequently, the vesicles could overcome the skin penetration difficulty by squeezing themselves through channels of the SC that are less than one-tenth of their diameter. ${ }^{7}$ Furthermore, the vesicles could induce a slight puffiness in corneocytes, due to the stress-dependent adaptability, which enables them to squeeze between the cells in the skin. ${ }^{6}$ The results showed that TFs and TE14 possessed a DI of $6.52 \pm 0.52$ and $14.94 \pm 0.63 \mathrm{~g}$, respectively. Statistical analysis showed that there was a significant difference $(P \leq 0.05)$ between the prepared formulae. The higher DI of TE14 could be attributed to the dual mechanism of both SAA and ethanol rather than SAA alone in case of TFs. It was reported by Maheshwari et $\mathrm{al}^{9}$ that ethanol has the potential to fluidize the skin lipids due to its interdigitation

Table 4 Effect of storage on the physical properties of TEI4

\begin{tabular}{l|l|l|l}
\hline Parameter & TEI4 fresh & $\begin{array}{l}\text { TEI4 after } \\
\mathbf{4 5} \text { days of } \\
\text { storage at } \mathbf{4}^{\circ} \mathbf{C}\end{array}$ & $\begin{array}{l}\text { TEI4 after } \\
\mathbf{4 5} \text { days of } \\
\text { storage at } 25^{\circ} \mathbf{C}\end{array}$ \\
\hline EE\% & $58.54 \pm I .30$ & $58.44 \pm I .13$ & $53.94 \pm 2.30$ \\
\hline PS $(\mathrm{nm})$ & $222.60 \pm 2.59$ & $222.00 \pm 15.00$ & $229.66 \pm 35.59$ \\
\hline PDI & $0.11 \pm 0.06$ & $0.14 \pm 0.02$ & $0.03 \pm 0.01$ \\
\hline ZP $(\mathrm{mV})$ & $-20.81 \pm 0.34$ & $-22.30 \pm 3.00$ & $-26.80 \pm 1.00$ \\
\hline Q6h $(\%)$ & $67.44 \pm 0.25$ & $67.57 \pm 0.05$ & $70.42 \pm 1.47$ \\
\hline
\end{tabular}

Note: Data are presented as mean \pm SD $(n=3)$.

Abbreviations: EE\%, entrapment efficiency percentage; PDI, polydispersity index; PS, particle size; Q6h, amount of drug released after 6 hours; TE, transethosome; $\mathrm{ZP}$, zeta potential. 
Table 5 Ex vivo permeation of OLM suspension, TFs, and TEI4 through rat skin and shed snake skin

\begin{tabular}{|c|c|c|c|c|}
\hline Formula & Skin type & $\begin{array}{l}\text { Total amount of drug permeated } \\
\text { per unit area in } 12 \mathrm{~h}\left(\mu \mathrm{g} / \mathrm{cm}^{2}\right)\end{array}$ & $J_{\max }\left(\mu \mathrm{g} / \mathrm{cm}^{2} / \mathrm{h}\right)$ & ER \\
\hline \multirow[t]{2}{*}{ OLM suspension } & Rat skin & $123.78 \pm 14.02$ & $10.32 \pm 1.10$ & 1.00 \\
\hline & Shed snake skin & $|46.35 \pm 8.7|$ & $12.19 \pm 0.72$ & 1.00 \\
\hline \multirow[t]{2}{*}{ TFs } & Rat skin & $564.20 \pm 0.82$ & $47.0 I \pm 0.06$ & 3.85 \\
\hline & Shed snake skin & $621.25 \pm 12.89$ & $51.77 \pm 1.07$ & 5.01 \\
\hline \multirow[t]{2}{*}{ TEI4 } & Rat skin & $\mathrm{I}, \mathrm{I} 54.04 \pm 167.74$ & $96.17 \pm 13.97$ & 7.88 \\
\hline & Shed snake skin & $1,519.68 \pm 363.84$ & $126.64 \pm 30.32$ & 12.27 \\
\hline
\end{tabular}

Note: Data are presented as mean $\pm \operatorname{SD}(n=3)$.

Abbreviations: ER, enhancement ratio; $J_{\max }$, maximum flux; OLM, olmesartan medoxomil; TE, transethosome; TFs, transferosomes.

effect on lipid bilayers, which leads to the formation of small pores as penetration pathways, hence justifying the superiority of TE14 over TFs.

\section{Ex vivo studies}

\section{Ex vivo permeation through rat skin and shed snake skin}

A wide range of animal models has been suggested as a suitable replacement for human skin and has been used to evaluate percutaneous permeation of drugs. The ex vivo permeation study was performed using two skin models: rat skin and shed snake skin. Rat skin is a full-thickness skin that consists of SC with underlying tissues of viable epidermis and dermis. ${ }^{61}$ Shed snake skin is a nonliving tissue which can be obtained without sacrifices. It consists of three layers beta, meso, and alpha layers - and is composed of two very different regions - scales and separating these, hinges; the scales are firm, while the hinges are soft. ${ }^{62}$ From Table 5, it could be concluded that the amount of OLM permeated from the formulae (TFs and TE14) was significantly higher than the amount permeated from OLM suspension $(P \leq 0.05)$. However, it was noticed that OLM permeated through both membranes in the same order: TE14 $>$ TFs $>$ OLM suspension (Figure 4). The significant lower permeability of OLM suspension than both vesicular formulations may be referred to the characteristics of the drug. It is believed that the high $\log P$-value of 5.6 might be the reason for the poor permeation of OLM. ${ }^{33}$ A characteristic parabolic relationship between the skin permeability and lipophilicity of various drugs has been previously reported with the maximum permeability at $\log P$ of approximately $3-4 .{ }^{63}$ For deformable vesicles, the case is different as studies have shown that these vesicles can penetrate as intact vesicles into the SC and thus the permeation of the drug is governed primarily by the permeability of the vesicles. ${ }^{3}$ The greater permeation of TE14 over TFs is probably attributed to the greater DI and elasticity of the former which would permit rapid motion of vesicles across the membrane. Moreover, the presence of ethanol in TEs may facilitate the penetration of the vesicles by fluidizing skin lipids which results in the formation of additional penetration pathways. ${ }^{9}$

It is worthy to note that shed snake skin showed numerically (not significantly) higher permeability parameters with $\mathrm{J}_{\max }$ of $51.77 \pm 1.07$ and $126.64 \pm 30.32 \mu \mathrm{g} / \mathrm{cm}^{2} / \mathrm{h}$ compared to $47.01 \pm 0.06$ and $96.17 \pm 13.97 \mu \mathrm{g} / \mathrm{cm}^{2} / \mathrm{h}$ of rat skin for both TFs and TE14, respectively. This might be related to the difference in thickness of both membranes. Thickness of shed snake skin is approximately $0.02-0.03 \mathrm{~mm},{ }^{64}$ while the thickness of hairless rat skin is $0.70-0.86 \mathrm{~mm} .{ }^{65}$ The obtained results justified the similarity of both skin types and the ability of utilizing them in further ex vivo studies.

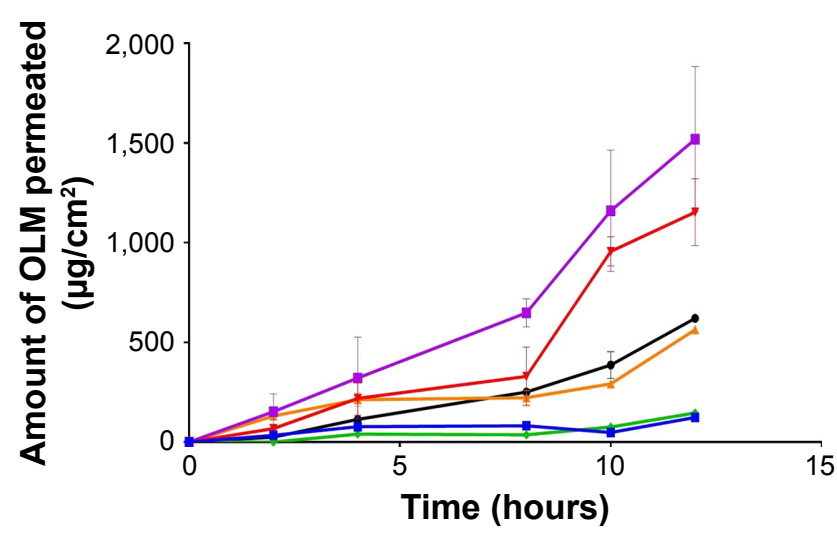

- OLM suspension from rat skin

- OLM suspension from shed snake skin

- TFs from rat skin

- TFs from shed snake skin

* TE14 from rat skin

- TE14 from shed snake skin

Figure 4 Cumulative amount of OLM permeated per unit area across excised rat and shed snake skin via TFs and TEI4 relative to drug suspension.

Abbreviations: OLM, olmesartan medoxomil; TFs, transferosomes; TE, transethosome. 


\section{Confocal laser scanning microscopy}

The efficacy of TE14 to permeate across skin was also examined by CLSM by utilizing a model lipid-soluble fluorophore (FDA) instead of OLM in TE14. Before imaging, we confirmed that the nontreated skin did not show any fluorescence in the detection range of the used fluorophore. Firstly, longitudinal section of the skin treated with $1 \%$ FDA solution (Figure 5A) showed slight distribution of the dye in different skin layers. Figure 5B, which represents a longitudinal section of the skin treated with fluoro-labeled TEs, shows the depth and the distribution of the dye through different skin layers. As observed from the previous figures, there was an extensive distribution of fluorescence throughout the skin layers from TEs compared to FDA solution. This might be related to the low penetration ability of FDA solution in contrast to the effective permeation of TE vesicles. Generally, skin permeation can occur through corneocytes as transcellular route, between corneocytes as paracellular route, and through appendages. ${ }^{66}$ In addition, intense fluorescence was apparent near the hair follicles because of accumulation of TEs in this area. Moreover, the use of the TEs increased fluorescence intensity and the depth of penetration through subcutaneous layer. This effect is expected to have a positive impact on improving drug bioavailability. In summary, CLSM confirmed that the fluorescence intensity of FDA at different skin layers was relatively higher when encapsulated in TEs using follicular pathway as the main penetration pathway. These findings also confirmed that TEs facilitated accumulation of the OLM into skin layers, followed by creating a micro-reservoir system to sustain drug release into skin layers. ${ }^{17}$

\section{In vivo studies}

TE14 showed higher elasticity and permeability compared to TFs. Further, CLSM was used to visualize the complete distribution of TE14 through different skin layers. Consequently, TE14 was subjected to further in vivo investigations.

\section{Histopathological study}

Skin irritation caused by permeation enhancers is considered a major limitation for transdermal administration. ${ }^{67}$ Light microscopy examination of groups II and III that were treated with OLM suspension and TE14, respectively, showed no histopathological alterations in epidermal and dermal cells when compared to untreated skin sections (group I) (Figure 6). These findings indicated that TE14 vesicles had acceptable tolerability.

\section{Pharmacodynamic study}

Administration of MPA elevated the BP above $150 \mathrm{mmHg}$ in normotensive rats. ${ }^{28}$ Transdermally applied TE14 vesicles showed the highest percentage reduction in BP at 4 hours
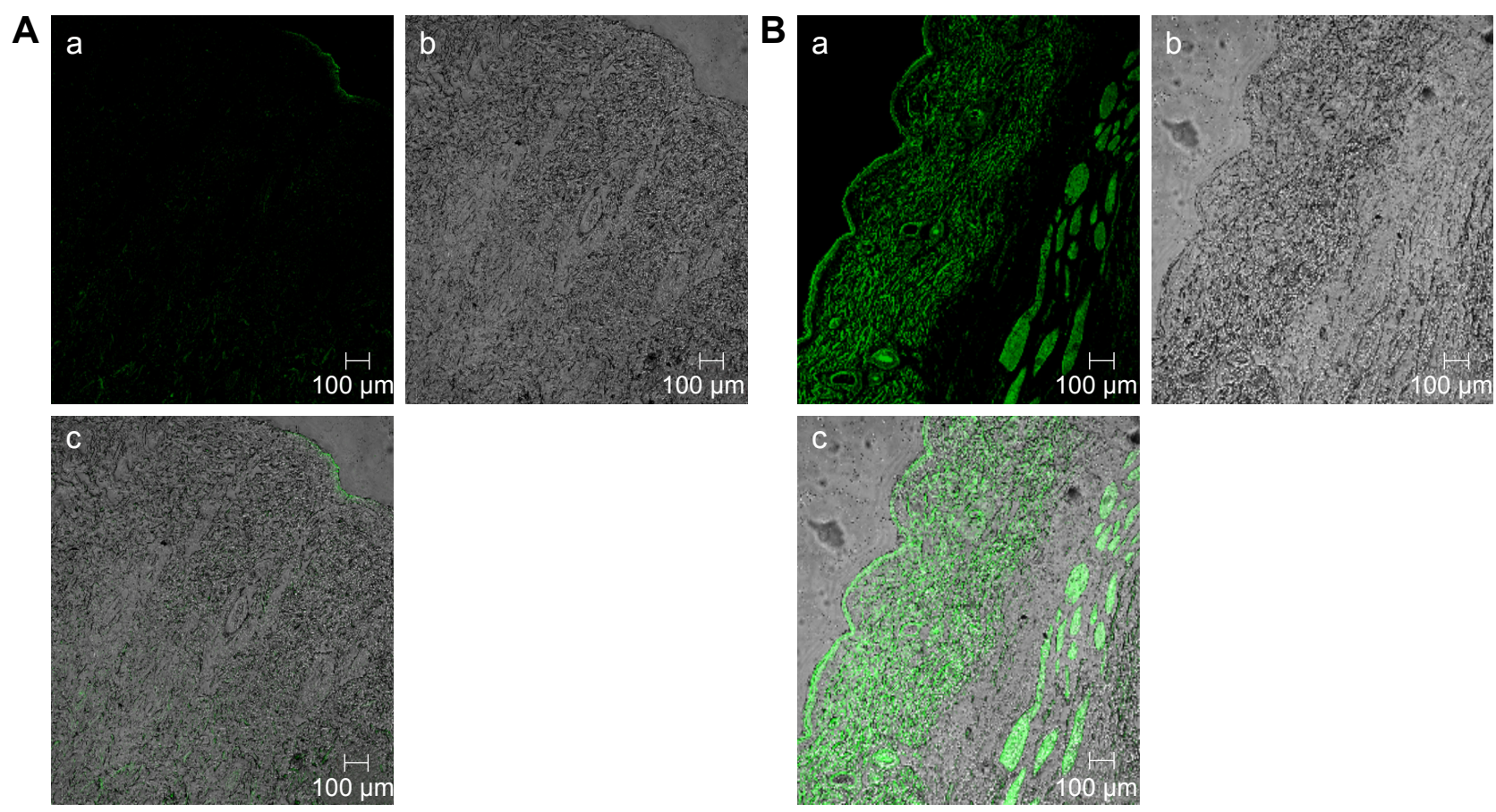

Figure 5 A tile scan confocal laser scanning microscope photomicrographs of (A) longitudinal section of rat skin treated with I\% FDA solution and (B) fluoro-labeled TEs: (a) fluorescence light, (b) transmitted light, and (c) merge between fluorescence light and transmitted light.

Abbreviations: FDA, fluorescein diacetate; TEs, transethosomes. 
A

B

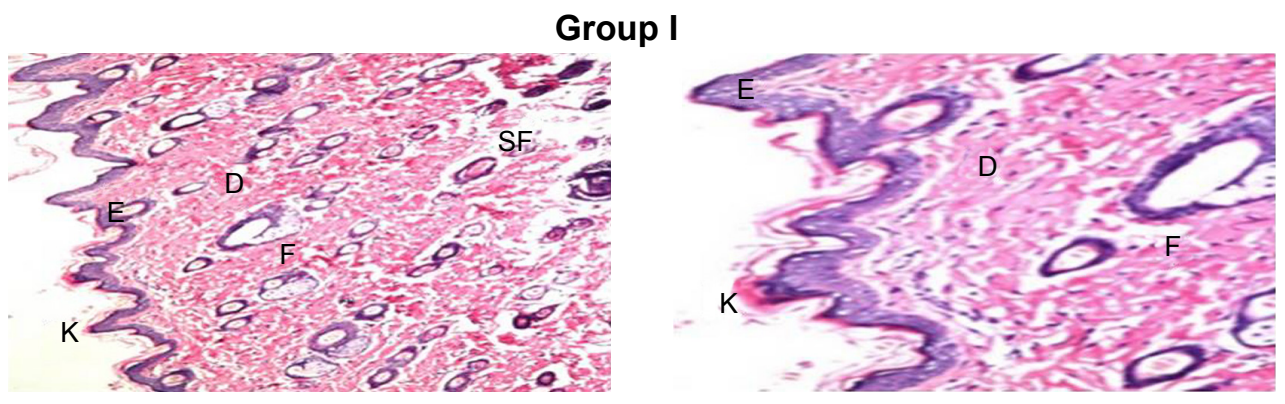

\section{Group II}
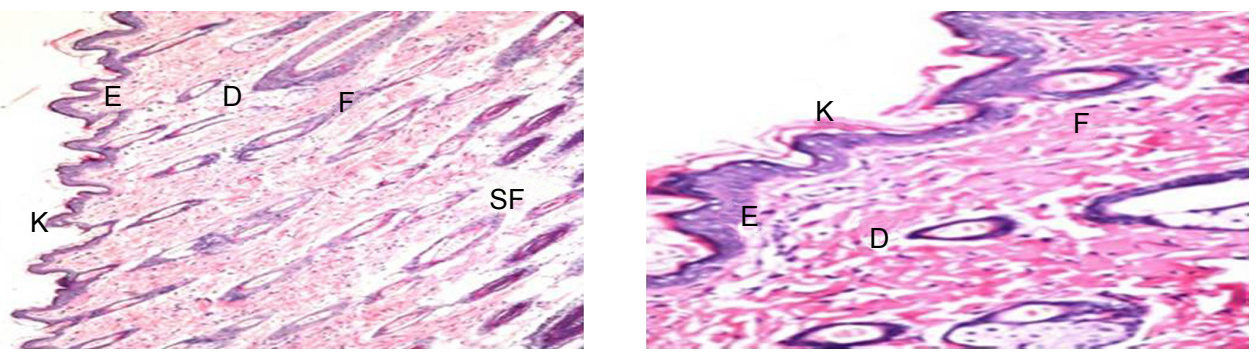

\section{Group III}
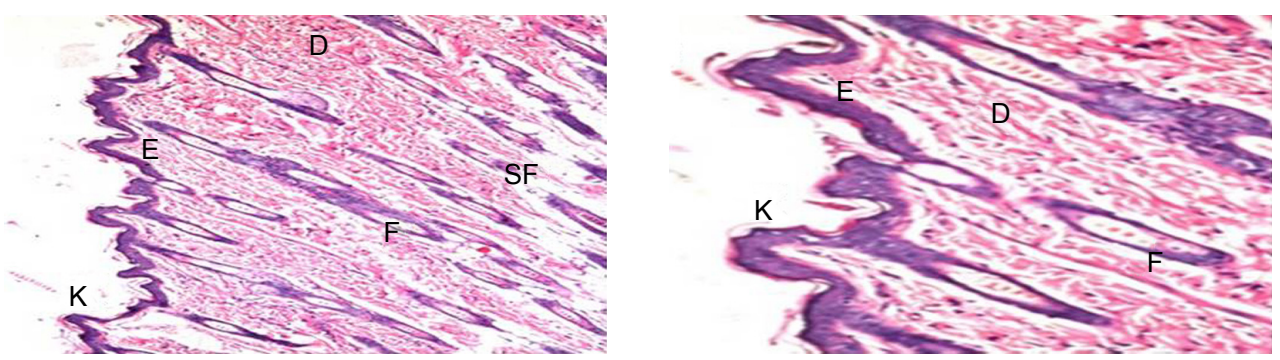

Figure 6 Photomicrographs showing histopathological sections (H\&E stained) of normal untreated rat skin (group I), rat skin treated with OLM suspension (group II), and rat skin treated with TEI4 (group III). The magnification power of $\times 16$ (A) to illustrate all skin layers and $\times 40$ (B) to identify the epidermis and dermis, respectively. Abbreviations: D, dermis; E, epidermis; F, hair follicles; K, keratin; OLM, olmesartan medoxomil; SF, subcutaneous fat; TE, transethosome.

$(35.00 \% \pm 12.00 \%)$, and BP was controlled for up to 24 hours (Table 6). This indicates that the drug permeated into systemic circulation in rats in a constant manner through TE14. Moreover, orally administered market tablet was able to maintain BP values at the normal level for up to 6 hours. After that, the market tablet failed to reduce the BP to normal value at 8 and 24 hours posttreatment. On the other hand, TE14 maintained normal BP values of $123.50 \pm 12.09$

Table 6 Influence of market tablet and TEI4 on mean blood pressure in MPA-induced hypertensive rats

\begin{tabular}{|l|l|l|l|l|l|l|}
\hline $\begin{array}{l}\text { Time } \\
(\text { hours) }\end{array}$ & $\begin{array}{l}\text { Negative control } \\
(\mathbf{m m H g})\end{array}$ & $\begin{array}{l}\text { HT positive } \\
\text { control } \mathbf{( m m H g})\end{array}$ & $\begin{array}{l}\text { Market tablet } \\
(\mathbf{m m H g})\end{array}$ & TEI4 (mmHg) & $\begin{array}{l}\text { \% reduction in BP } \\
\text { by market tablet }\end{array}$ & $\begin{array}{l}\text { \% reduction in } \\
\text { BP by TE I4 }\end{array}$ \\
\hline 0 & $109.50 \pm 3.50$ & $171.00 \pm 4.00$ & $177.00 \pm 3.26$ & $167.20 \pm 4.86$ & $4.00 \% \pm 2.00 \%$ & $3.00 \% \pm 2.00 \%$ \\
\hline 1 & $126.20 \pm 1.20$ & $187.50 \pm 2.50$ & $138.00 \pm 0.81$ & $142.00 \pm 29.35$ & $26.00 \% \pm 0.00 \%$ & $25.00 \% \pm 15.00 \%$ \\
\hline 2 & $129.00 \pm 1.00$ & $166.50 \pm 6.50$ & $127.20 \pm 1.83$ & $120.00 \pm 6.96$ & $24.00 \% \pm 1.00 \%$ & $28.00 \% \pm 4.00 \%$ \\
\hline 4 & $126.70 \pm 2.70$ & $168.00 \pm 8.00$ & $128.90 \pm 0.83$ & $109.70 \pm 19.49$ & $23.00 \% \pm 1.00 \%$ & $35.00 \% \pm 12.00 \%$ \\
\hline 6 & $117.70 \pm 4.20$ & $166.00 \pm 4.00$ & $126.50 \pm 6.94$ & $126.20 \pm 4.60$ & $24.00 \% \pm 4.00 \%$ & $24.00 \% \pm 3.00 \%$ \\
\hline 8 & $114.70 \pm 1.70$ & $169.50 \pm 2.50$ & $140.10 \pm 6.40$ & $123.50 \pm 12.09$ & $17.00 \% \pm 4.00 \%$ & $27.00 \% \pm 7.00 \%$ \\
\hline 24 & $117.70 \pm 0.70$ & $185.50 \pm 5.50$ & $165.00 \pm 8.16$ & $127.50 \pm 4.33$ & $11.00 \% \pm 4.00 \%$ & $31.00 \% \pm 2.00 \%$ \\
\hline
\end{tabular}

Note: Data are presented as mean $\pm S D(n=6)$.

Abbreviations: BP, blood pressure; HT, hypertensive; MPA, methyl prednisolone acetate; TE, transethosome. 
and $127.50 \pm 4.33 \mathrm{mmHg}$ at 8 and 24 hours posttreatment, respectively. By comparing the effects of the treatments, the percentage reduction in mean rat BP by market tablet and TE14 was found to be $11.00 \% \pm 4.00 \%$ and $31.00 \% \pm 2.00 \%$, respectively, at 24 hours posttreatment which confirmed that TE14 showed better antihypertensive activity in rat model in comparison with market tablet. Furthermore, post hoc analysis showed that there was no significant difference $(P \geq 0.05)$ between the negative control group and TE14treated group while there was a significant difference between market tablet-treated group and the negative control group at 24 hours posttreatment. These findings indicated that the developed vesicles were effective in returning the BP of MPA-induced hypertensive rats to normal values.

\section{Dermatokinetic study}

Dermatokinetic study is performed for determination of the amount of drug deposited in the skin. ${ }^{68}$ The amount of OLM deposited from drug suspension and TE14 through rat skin at different time intervals is depicted in Figure 7. The skin treated with TE14 showed a significantly higher $\mathrm{C}_{\max }$ of $108.04 \pm 6.44 \mu \mathrm{g} / \mathrm{cm}^{2}$ and an $\mathrm{AUC}_{0-10}$ of $680.46 \pm 17.99$ $\mu \mathrm{g} \cdot \mathrm{h} / \mathrm{cm}^{2}$ in the skin layers when compared to the drug suspension with a $\mathrm{C}_{\max }$ of $47.07 \pm 32.40 \mu \mathrm{g} / \mathrm{cm}^{2}$ and an $\mathrm{AUC}_{0-10}$ of $196.30 \pm 99.66 \mu \mathrm{g} \cdot \mathrm{h} / \mathrm{cm}^{2}(P<0.05)$. This could be related to the potency of SDC in the transethosomal constructs to form chemical bonding with keratocytes in the skin via electrostatic interaction of its anionic head group with the cationic sites of skin proteins. Hence, vesicles acted as drug carriers which not only softened the intercellular matrix of SC but also penetrated deeply to the target site of dermis where a depot from which the drug can be released was formed. ${ }^{24}$ Furthermore, there was

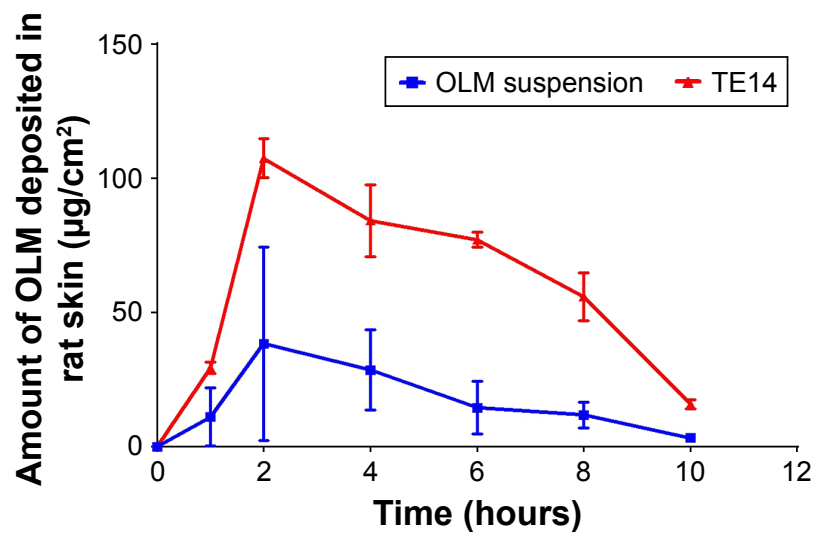

Figure 7 Dermatokinetic study of TEI4 and OLM suspension after topical application. Abbreviations: OLM, olmesartan medoxomil; TE, transethosome. no significant difference between the $\mathrm{T}_{\max }$ of TE14 when compared to drug suspension.

\section{Conclusion}

In this work, TEs were formulated as transdermal delivery system for OLM. Fifteen formulae were prepared using thin-film hydration technique according to $5^{1} \cdot 3^{1}$ full factorial design which was used to select the optimum formula (TE14) that displayed spherical morphology, reasonable drug EE\%, small PS, and high OLM release. Moreover, TE14 was subjected to DSC studies which confirmed the entrapment of OLM within the transethosomal structure. The elasticity measurement and evaluation of ex vivo skin permeation using both rat and shed snake skin confirmed the superiority of TE14 over TFs due to the presence of both SAA and ethanol. CLSM further confirmed the potential of TEs to overcome the SC and penetrate deeply within the skin layers. Further, the in vivo histopathological study confirmed the non-irritancy of TE14 when applied on rat skin. Additionally, TE14 showed superiority over market tablet in pharmacodynamic study and was able to maintain BP at normal values for 24 hours. Moreover, dermatokinetic study showed significantly higher $\mathrm{C}_{\text {max }}$ and $\mathrm{AUC}_{0-10}$ for TE14 when compared to drug suspension due to higher retention capacity of vesicles in rat skin. Taken together, the results confirmed that TEs could be considered as promising transdermal delivery system for OLM as they can avoid extensive first-pass metabolism of OLM. Further studies are needed to establish the therapeutic activity of TE14 in humans.

\section{Disclosure}

The authors report no conflicts of interest in this work.

\section{References}

1. Chen M, Liu X, Fahr A. Skin penetration and deposition of carboxyfluorescein and temoporfin from different lipid vesicular systems: in vitro study with finite and infinite dosage application. Int J Pharm. 2011; 408(1-2):223-234.

2. Sivaraman A, Banga AK. Novel in situ forming hydrogel microneedles for transdermal drug delivery. Drug Deliv Transl Res. 2017;7(1): $16-26$.

3. Knudsen Nina Ø, Rønholt S, Salte RD, et al. Calcipotriol delivery into the skin with pegylated liposomes. Eur J Pharm Biopharm. 2012; 81(3):532-539.

4. Alsofany JM, Hamza MY, Abdelbary AA. Fabrication of nanosuspension directly loaded fast-dissolving films for enhanced oral bioavailability of olmesartan medoxomil: in vitro characterization and pharmacokinetic evaluation in healthy human volunteers. AAPS PharmSciTech. 2018;19(5):2118-2132.

5. Ashtikar M, Nagarsekar K, Fahr A. Transdermal delivery from liposomal formulations - Evolution of the technology over the last three decades. J Control Release. 2016;242:126-140. 
6. Cevc G, Schätzlein A, Richardsen H. Ultradeformable lipid vesicles can penetrate the skin and other semi-permeable barriers unfragmented. Evidence from double label CLSM experiments and direct size measurements. Biochimica et Biophysica Acta (BBA) - Biomembranes. 2002; 1564(1):21-30.

7. Al Shuwaili AH, Rasool BKA, Abdulrasool AA. Optimization of elastic Transfersomes formulations for transdermal delivery of pentoxifylline. Eur J Pharm Biopharm. 2016;102:101-114.

8. Touitou E, Godin B, Dayan N, Weiss C, Piliponsky A, Levi-Schaffer F. Intracellular delivery mediated by an ethosomal carrier. Biomaterials. 2001;22(22):3053-3059.

9. Maheshwari RGS, Tekade RK, Sharma PA, et al. Ethosomes and ultradeformable liposomes for transdermal delivery of clotrimazole: a comparative assessment. Saudi Pharm J. 2012;20(2):161-170.

10. Garg V, Singh H, Bhatia A, et al. Systematic development of Transethosomal gel system of piroxicam: formulation optimization, in vitro evaluation, and ex vivo assessment. AAPS PharmSciTech. 2017;18(1): 58-71.

11. Kumar A, Pathak K, Bali V. Ultra-adaptable nanovesicular systems: a carrier for systemic delivery of therapeutic agents. Drug Discov Today. 2012;17(21-22):1233-1241.

12. Kamran M, Ahad A, Aqil M, Imam SS, Sultana Y, Ali A. Design, formulation and optimization of novel soft nano-carriers for transdermal olmesartan medoxomil delivery: In vitro characterization and in vivo pharmacokinetic assessment. Int J Pharm. 2016;505(1-2): $147-158$.

13. Hathout RM, Elshafeey AH. Development and characterization of colloidal soft nano-carriers for transdermal delivery and bioavailability enhancement of an angiotensin II receptor blocker. Eur J Pharm Biopharm. 2012;82(2):230-240.

14. Refai H, Hassan D, Abdelmonem R. Development and characterization of polymer-coated liposomes for vaginal delivery of sildenafil citrate. Drug Deliv. 2017;24(1):278-288.

15. Varona S, Martín A, Cocero MJ. Liposomal incorporation of lavandin essential oil by a thin-film hydration method and by particles from gas-saturated solutions. Ind Eng Chem Res. 2011;50(4): 2088-2097.

16. Dimitrov D, Li J, Angelova M, Jain R. Surface effects in preparation of cell-size liposomes. FEBS Letters. 1984;176(2):398-400.

17. Abdellatif MM, Khalil IA, Khalil MAF. Sertaconazole nitrate loaded nanovesicular systems for targeting skin fungal infection: In-vitro, ex-vivo and in-vivo evaluation. Int J Pharm. 2017;527(1-2): $1-11$.

18. Abdelbary A, Al-Mahallawi A, Abdelrahim M, Ali A. Preparation, optimization, and in vitro simulated inhalation delivery of carvedilol nanoparticles loaded on a coarse carrier intended for pulmonary administration. Int J Nanomedicine. 2015;10:6339-6353.

19. Safwat S, Ishak RAH, Hathout RM, Mortada ND. Nanostructured lipid carriers loaded with simvastatin: effect of PEG/glycerides on characterization, stability, cellular uptake efficiency and in vitro cytotoxicity. Drug Dev Ind Pharm. 2017;43(7):1112-1125.

20. Zeb A, Qureshi OS, Kim HS, Cha JH, Kim JK. Improved skin permeation of methotrexate via nanosized ultradeformable liposomes Int J Nanomedicine. 2016;11:3813-3824.

21. Al-Mahallawi AM, Khowessah OM, Shoukri RA. Nano-transfersomal ciprofloxacin loaded vesicles for non-invasive trans-tympanic ototopical delivery: in-vitro optimization, ex-vivo permeation studies, and in-vivo assessment. Int J Pharm. 2014;472(1-2):304-314.

22. El Zaafarany GM, Awad GAS, Holayel SM, Mortada ND. Role of edge activators and surface charge in developing ultradeformable vesicles with enhanced skin delivery. Int J Pharm. 2010;397(1-2): 164-172.

23. Kassem AA, Abd El-Alim SH, Asfour MH. Enhancement of 8-methoxypsoralen topical delivery via nanosized niosomal vesicles: Formulation development, in vitro and in vivo evaluation of skin deposition. Int J Pharm. 2017;517(1-2):256-268.
24. Aziz DE, Abdelbary AA, Elassasy AI. Investigating superiority of novel bilosomes over niosomes in the transdermal delivery of diacerein: in vitro characterization, ex vivo permeation and in vivo skin deposition study. J Liposome Res. 2019;29(1):73-85.

25. Abdelbary AA, Aboughaly MHH. Design and optimization of topical methotrexate loaded niosomes for enhanced management of psoriasis: application of Box-Behnken design, in-vitro evaluation and in-vivo skin deposition study. Int J Pharm. 2015;485(1-2):235-243.

26. Al-Mahallawi AM, Abdelbary AA, Aburahma MH. Investigating the potential of employing bilosomes as a novel vesicular carrier for transdermal delivery of tenoxicam. Int J Pharm. 2015;485(1-2): 329-340.

27. Turner PV, Brabb T, Pekow C, Vasbinder MA. Administration of substances to laboratory animals: routes of administration and factors to consider. J Am Assoc Lab Anim Sci. 2011;50(5):600-613.

28. Ahad A, Aqil M, Kohli K, Sultana Y, Mujeeb M, Ali A. Formulation and optimization of nanotransfersomes using experimental design technique for accentuated transdermal delivery of valsartan. Nanomedicine. 2012;8(2):237-249.

29. Alexander DLJ, Tropsha A, Winkler DA. Beware of $R^{(2)}$ : Simple, unambiguous assessment of the prediction accuracy of QSAR and QSPR models. J Chem Inf Model. 2015;55(7):1316-1322.

30. Mendes AC, Gorzelanny C, Halter N, Schneider SW, Chronakis IS. Hybrid electrospun chitosan-phospholipids nanofibers for transdermal drug delivery. Int J Pharm. 2016;510(1):48-56.

31. Aboud HM, Ali AA, El-Menshawe SF, Elbary AA. Nanotransfersomes of carvedilol for intranasal delivery: formulation, characterization and in vivo evaluation. Drug Deliv. 2016;23(7):2471-2481.

32. Kunieda H, Ohyama K-Ichi. Three-phase behavior and HLB numbers of bile salts and lecithin in a water-oil system. J Colloid Interface Sci. 1990;136(2):432-439.

33. B A, D N, Veerabrahma K. Development of olmesartan medoxomil lipid-based nanoparticles and nanosuspension: preparation, characterization and comparative pharmacokinetic evaluation. Artif Cells Nanomed Biotechnol. 2018;46(1):126-137.

34. Junyaprasert VB, Singhsa P, Suksiriworapong J, Chantasart D. Physicochemical properties and skin permeation of span 60/Tween 60 niosomes of ellagic acid. Int J Pharm. 2012;423(2):303-311.

35. El-Say KM, Abd-Allah FI, Lila AE, Hassan AE-SA, Kassem AEA. Diacerein niosomal gel for topical delivery: development, in vitro and in vivo assessment. J Liposome Res. 2016;26(1):57-68.

36. Mokhtar M, Sammour OA, Hammad MA, Megrab NA. Effect of some formulation parameters on flurbiprofen encapsulation and release rates of niosomes prepared from proniosomes. Int J Pharm. 2008;361(1-2) 104-111.

37. Bnyan R, Khan I, Ehtezazi T, et al. Surfactant effects on lipid-based vesicles properties. J Pharm Sci. 2018;107(5):1237-1246.

38. Ezzat SM, Salama MM, Elmeshad AN, Teaima MH, Rashad LA. HPLC-DAD-MS/MS profiling of standardized rosemary extract and enhancement of its anti-wrinkle activity by encapsulation in elastic nanovesicles. Arch Pharm Res. 2016;39(7):912-925.

39. Singh B, Mehta G, Kumar R, Bhatia A, Ahuja N, Katare OP. Design, development and optimization of nimesulide-loaded liposomal systems for topical application. Curr Drug Deliv. 2005;2(2):143-153.

40. Das S, Ng WK, Tan RB. Are nanostructured lipid carriers (NLCs) better than solid lipid nanoparticles (SLNs): development, characterizations and comparative evaluations of clotrimazole-loaded SLNs and NLCs? Eur J Pharm Sci. 2012;47(1):139-151.

41. Yeo L, Olusanya T, Chaw C, Elkordy A. Brief effect of a small hydrophobic drug (cinnarizine) on the physicochemical characterisation of Niosomes produced by thin-film hydration and microfluidic methods. Pharmaceutics. 2018;10(4):185.

42. Akhter S, Kushwaha S, Warsi MH, et al. Development and evaluation of nanosized niosomal dispersion for oral delivery of ganciclovir. Drug Dev Ind Pharm. 2012;38(1):84-92. 
43. Chen Y, Qiao F, Fan Y, Han Y, Wang Y. Interactions of Cationic/ Anionic mixed surfactant aggregates with phospholipid vesicles and their skin penetration ability. Langmuir. 2017;33(11):2760-2769.

44. Hathout RM, Mansour S, Mortada ND, Guinedi AS. Liposomes as an ocular delivery system for acetazolamide: in vitro and in vivo studies. AAPS PharmSciTech. 2007;8(1):E1-E12.

45. Salama AH, Aburahma MH. Ufasomes nano-vesicles-based lyophilized platforms for intranasal delivery of cinnarizine: preparation, optimization, ex-vivo histopathological safety assessment and mucosal confocal imaging. Pharm Dev Technol. 2016;21(6):706-715.

46. Khalil RM, Abdelbary GA, Basha M, Awad GEA, El-Hashemy HA. Enhancement of lomefloxacin Hcl ocular efficacy via niosomal encapsulation: in vitro characterization and in vivo evaluation. J Liposome Res. 2017;27(4):312-323.

47. Kim JY, Song MG, Kim JD. Zeta Potential of Nanobubbles Generated by Ultrasonication in Aqueous Alkyl Polyglycoside Solutions. J Colloid Interface Sci. 2000;223(2):285-291.

48. Ibrahim N, Raman IA, Yusop MR. Effects of functional group of non-ionic surfactants on the stability of emulsion. MJAS. 2015;19(1): 261-267.

49. Nagaich U, Gulati N. Nanostructured lipid carriers (NLC) based controlled release topical gel of clobetasol propionate: design and in vivo characterization. Drug Deliv Transl Res. 2016;6(3):289-298.

50. Garcia-Manyes S, Oncins G, Sanz F. Effect of pH and ionic strength on phospholipid nanomechanics and on deposition process onto hydrophilic surfaces measured by AFM. Electrochimica Acta. 2006;51(24):5029-5036.

51. Papahadjopoulos D, Miller N. Phospholipid model membranes. I. Structural characteristics of hydrated liquid crystals. Biochim Biophys Acta. 1967;135(4):624-638.

52. Egawa H, Furusawa K. Liposome adhesion on mica surface studied by atomic force microscopy. Langmuir. 1999;15(5):1660-1666.

53. Makino K, Yamada T, Kimura M, Oka T, Ohshima H, Kondo T. Temperature- and ionic strength-induced conformational changes in the lipid head group region of liposomes as suggested by zeta potential data. Biophys Chem. 1991;41(2):175-183.

54. Jain S, Jain P, Umamaheshwari RB, Jain NK. Transfersomes - a novel vesicular carrier for enhanced transdermal delivery: development, characterization, and performance evaluation. Drug Dev Ind Pharm. 2003; 29(9):1013-1026.

55. Kriwet K, Müller-Goymann CC. Diclofenac release from phospholipid drug systems and permeation through excised human stratum corneum. Int J Pharm. 1995;125(2):231-242.

56. Hinze WL, Pramauro E. A critical review of Surfactant-Mediated phase separations (cloud-point extractions): theory and applications. Crit Rev Anal Chem. 1993;24(2):133-177.
57. Villasmil-Sánchez S, Rabasco AM, González-Rodríguez ML. Thermal and 31P-NMR studies to elucidate sumatriptan succinate entrapment behavior in phosphatidylcholine/cholesterol liposomes. Comparative 31P-NMR analysis on negatively and positively-charged liposomes. Colloids Surf B Biointerfaces. 2013;105:14-23.

58. Suzuki H, Ogawa M, Hironaka K, Ito K, Sunada H. A nifedipine coground mixture with sodium deoxycholate. II. Dissolution characteristics and stability. Drug Dev Ind Pharm. 2001;27(9):951-958.

59. Elsayed I, Abdelbary AA, Elshafeey AH. Nanosizing of a poorly soluble drug: technique optimization, factorial analysis, and pharmacokinetic study in healthy human volunteers. Int J Nanomedicine. 2014;9: 2943-2953.

60. El-Sayed MM, Hussein AK, Sarhan HA, Mansour HF. Flurbiprofenloaded niosomes-in-gel system improves the ocular bioavailability of flurbiprofen in the aqueous humor. Drug Dev Ind Pharm. 2017;43(6): 902-910.

61. Harada K, Murakami T, Kawasaki E, Higashi Y, Yamamoto S, Yata N. In-vitro permeability to salicylic acid of human, rodent, and shed snake skin. J Pharm Pharmacol. 1993;45(5):414-418.

62. Priprem A, Khamlert C, Pongjanyak T, Radapong S, Rittirod T, Chitropas P. Comparative permeation studies between scale region of shed snake skin and human skin in vitro. Am J Agric Biol Sci. 2008; $3(1): 444-450$.

63. Kim MK, Lee CH, Kim DD. Skin permeation of testosterone and its ester derivatives in rats. $J$ Pharm Pharmacol. 2000;52(4):369-375.

64. Ngawhirunpat T, Opanasopit P, Rojanarata T, Panomsuk S, Chanchome L. Evaluation of simultaneous permeation and metabolism of methyl nicotinate in human, snake, and shed snake skin. Pharm Dev Technol. 2008;13(1):75-83.

65. Todo H. Transdermal permeation of drugs in various animal species. Pharmaceutics. 2017;9(3):33.

66. Shamma RN, Aburahma MH. Follicular delivery of spironolactone via nanostructured lipid carriers for management of alopecia. Int $J$ Nanomedicine. 2014;9:5449-5460.

67. Priyanka K, Singh S. A review on skin targeted delivery of bioactives as ultradeformable vesicles: overcoming the penetration problem. Curr Drug Targets. 2014;15(2):184-198.

68. Moolakkadath T, Aqil M, Ahad A, et al. Development of transethosomes formulation for dermal fisetin delivery: Box-Behnken design, optimization, in vitro skin penetration, vesicles-skin interaction and dermatokinetic studies. Artif Cells Nanomed Biotechnol. 2018;46(Suppl 2): $755-765$.
International Journal of Nanomedicine

\section{Publish your work in this journal}

The International Journal of Nanomedicine is an international, peerreviewed journal focusing on the application of nanotechnology in diagnostics, therapeutics, and drug delivery systems throughout the biomedical field. This journal is indexed on PubMed Central, MedLine, CAS, SciSearch $®$, Current Contents ${ }^{\circledR} /$ Clinical Medicine,

\section{Dovepress}

Journal Citation Reports/Science Edition, EMBase, Scopus and the Elsevier Bibliographic databases. The manuscript management system is completely online and includes a very quick and fair peer-review system, which is all easy to use. Visit http://www.dovepress.com/ testimonials.php to read real quotes from published authors. 